\title{
سبق الإسلام تأريخيًا وتفوقه في إرساء حقوق الإنسان \\ (دراسة مقارنة بين التشريع الإسلامي والنظم الوضعية)
}

\author{
يوسف عبد الله مصطفى عبد الرازق \\ كلية التربية جامعة الجزبرة الحصاحيصيا السودان السوان
}

Email: yousifabdallah2011@gmail.com

الملخص

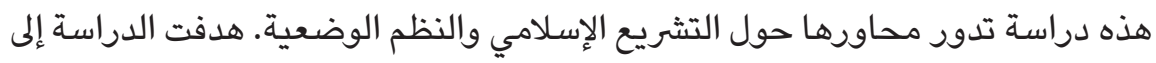

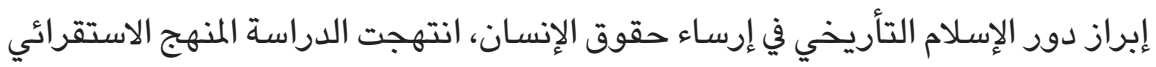

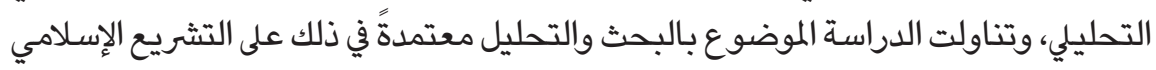

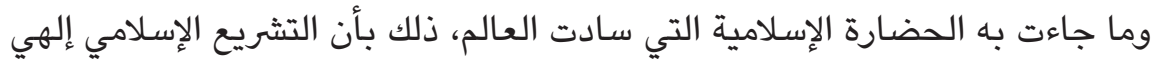

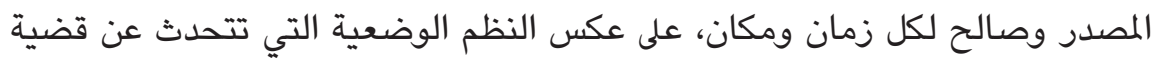

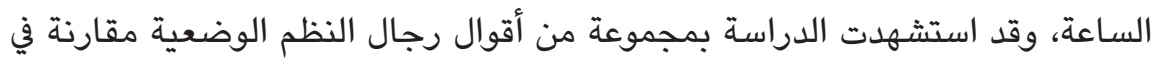

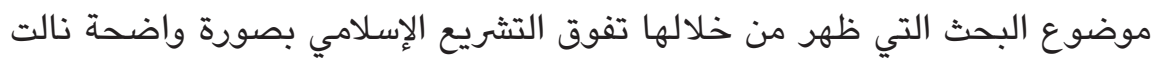
إعجاب واعتراف كثير من العلماء والمفكرين في العالم.

This study covers Islamic law and positive law, which aims to show the role of Islam in the history of establishing human rights. It employs inductive analytic approach. Hence, it mainly refers to the law of Islam (Islamic tasyri') and what is brought by Islamic civilization leading the world. It is due to the fact that Islamic tasyri' comes from Allah and is worth of all time and place. On the contrary, the positive law made by man deals with the problems related to time and conditions. This study is supported by legal experts to compare both laws. The finding shows the obvious advantage of Islamic tasyri' rather than other regulation or positive law. Its overwhelming advantage is also confirmed by world legal experts. 
الكلمات المفتاحيت: الإسلام؛ التشريع الإسلامي؛ حقوق الإنسان؛ النظم الوضعية.

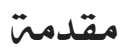
الحمد لله رب العالمين والصلاة والسلام على أشرف المرسلين سيدنا محمد صلى الله

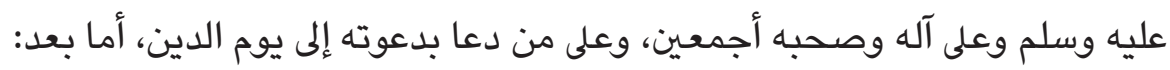

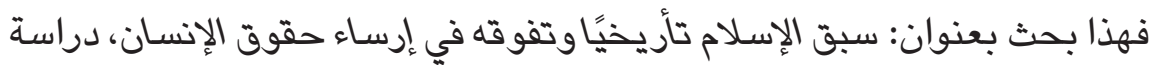

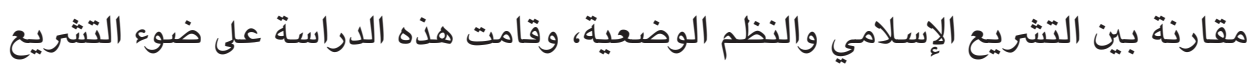

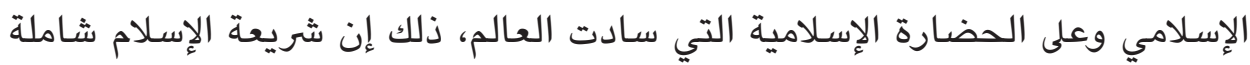

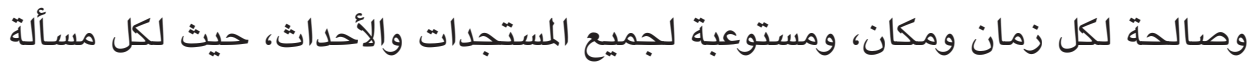

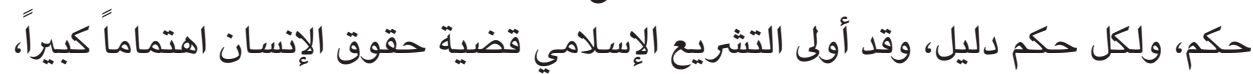

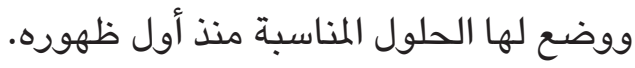

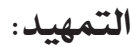

\section{الإسلام يساوي يين الناس جميعاً}

من المعلوم أن قضية حقوق الإنسان أصبحت حديث الناس في هذا العصر، وكثر

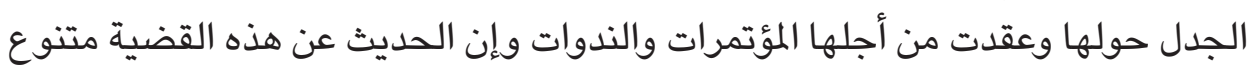

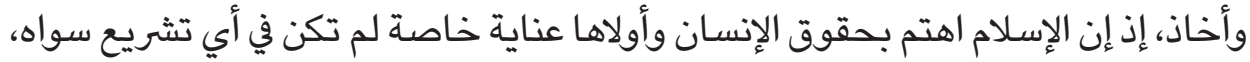

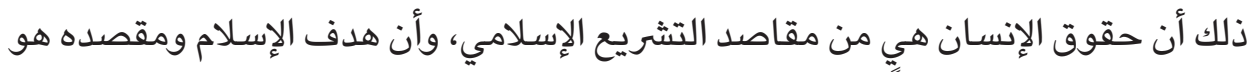

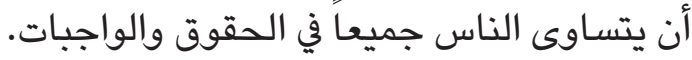

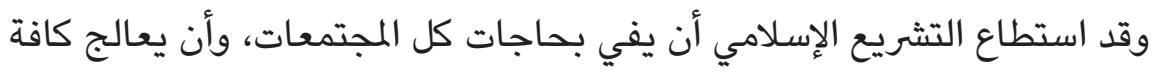

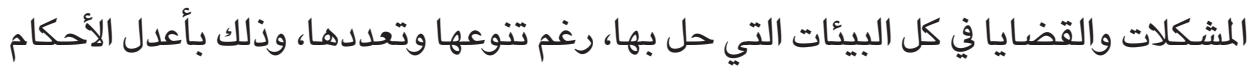

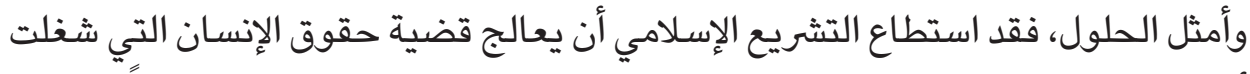
أذهان الناس منذ زمن بعيد، وذلك بإنصافه وإعطائه حقوقه، وجعل الإعل الناس جميعاً سواسية

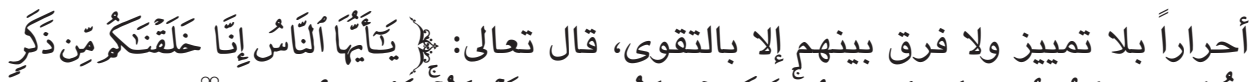

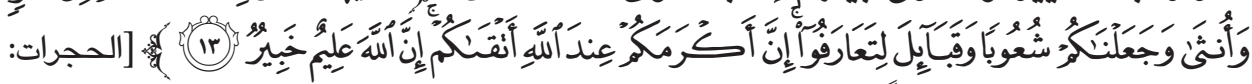

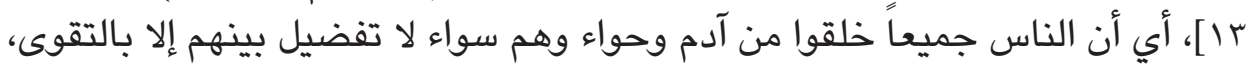

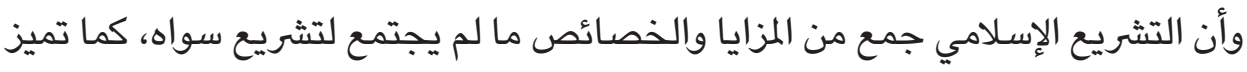

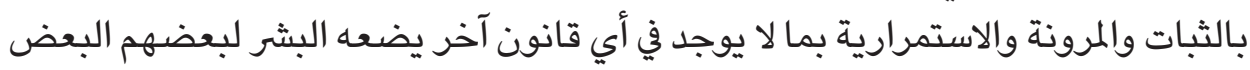




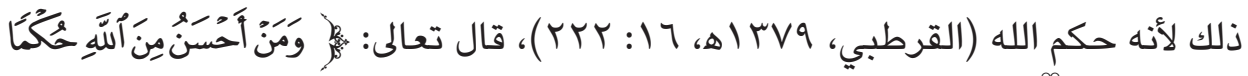

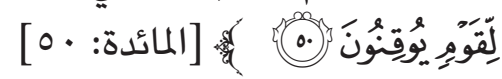

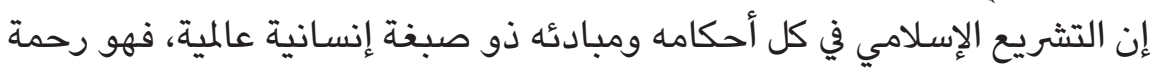

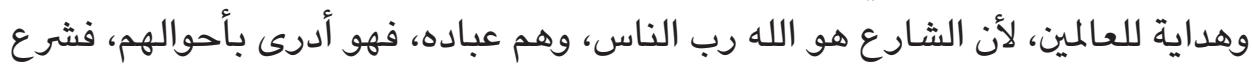

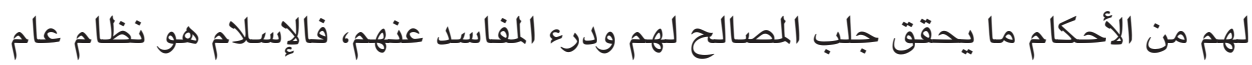

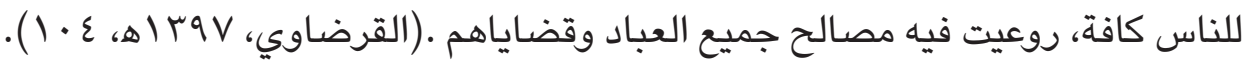
فموقف الإسلام من قضية حقوق الإنسان جلي وواضح، ويدل على سمو هذا الدين وكماله،

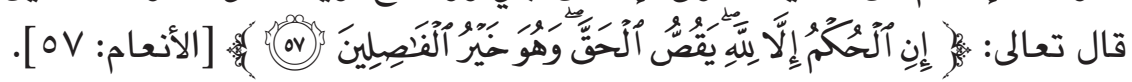

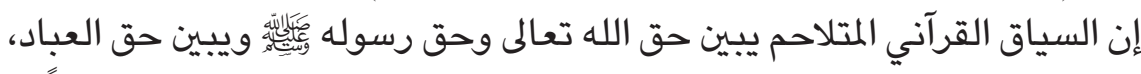

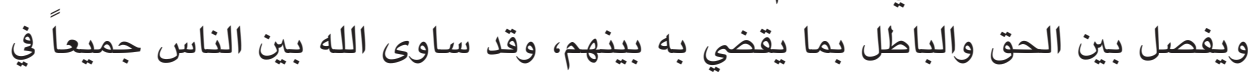

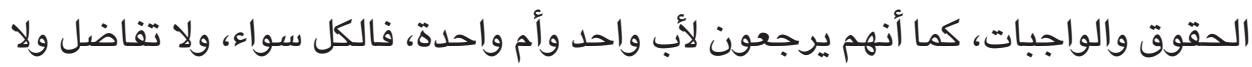

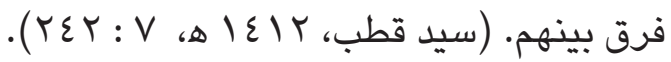

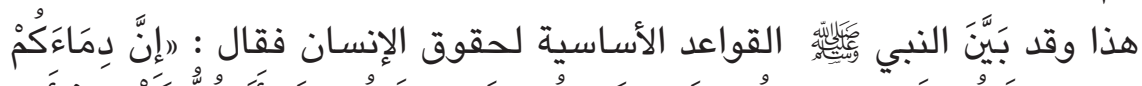

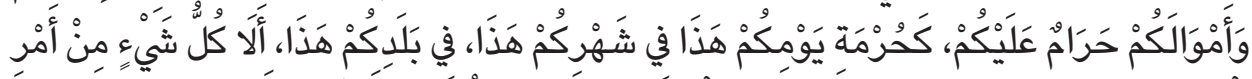

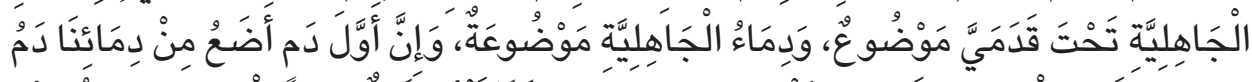

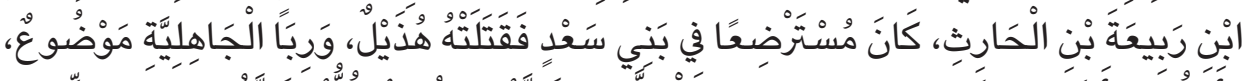

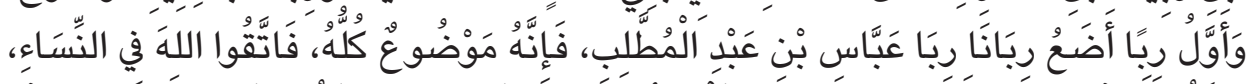

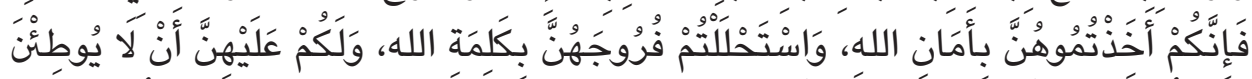

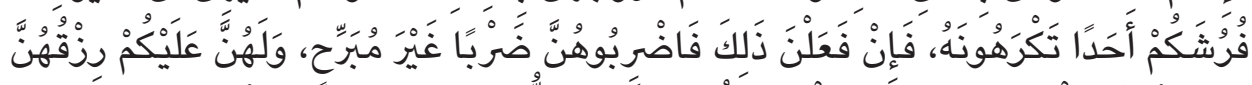

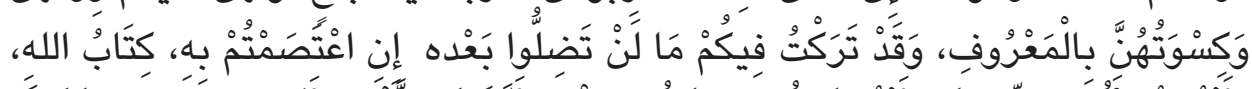

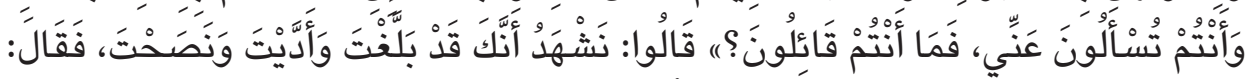

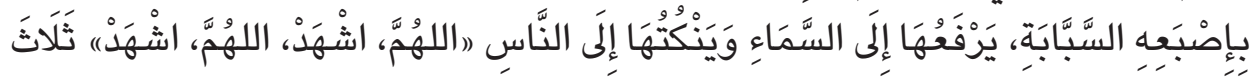

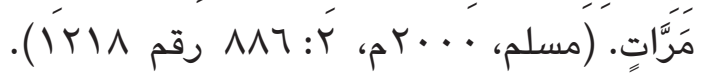

إن الإسلام اهتم بإنصاف الإنسان وإعطائه حقوقه، لا سيما المرأة فقد أعطاها حقوقها كاملة وحفظ لها مكانتها في المجتمع، كما أعطى المملوك حقه ويتضح ذانس ذلك حينما

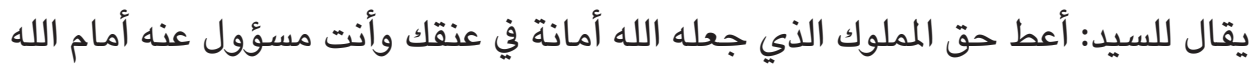

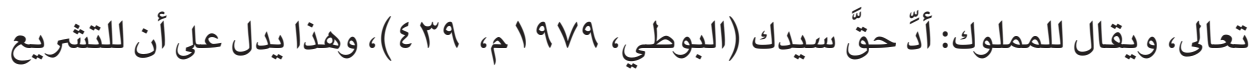

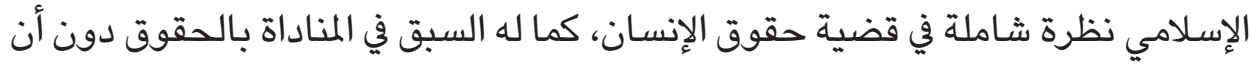


يتبناها المنادي لأغراضه الشخصية، نظرة لإيجاد انسجام وترابط وتراحم بين المسلمين

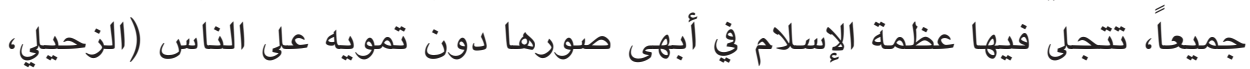

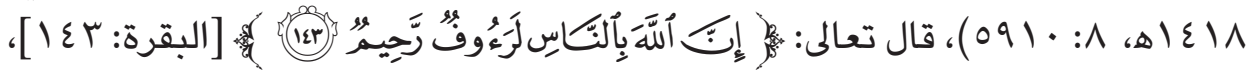

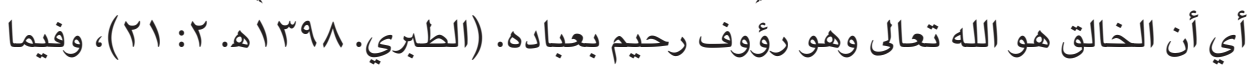
يلي ندخل على مباحث الدراسة.

المبحث الأول: المناداة بحقوق الإنسان

المطلب الأول: تعريف الحق لغت واصطلاححاً:

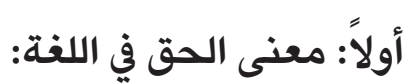

الحق مفرد الحقوق، والحق خلاف الباطل، وهو مصدر (حقّ) ويقال حقّ الشيء إذا

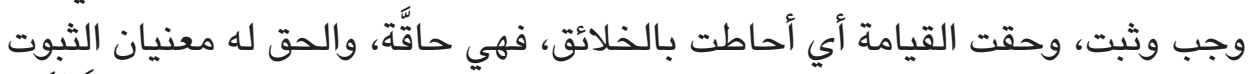

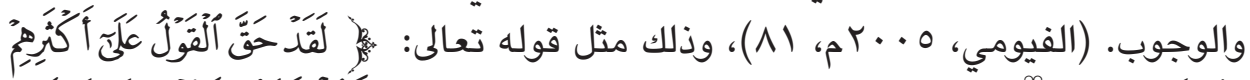

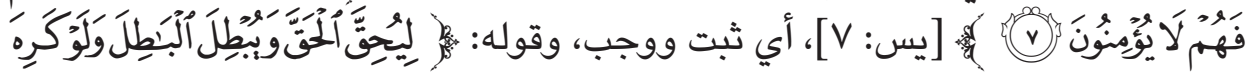

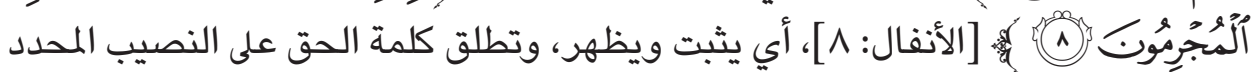
كمثل قوله تعالى:

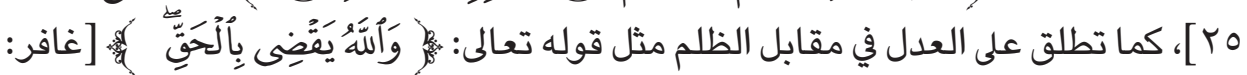

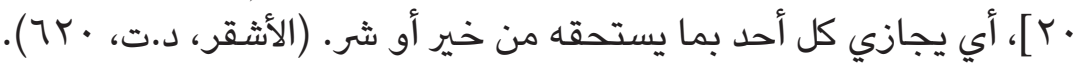

ثانياً: معنى الحق في الاصطلاح: الحق في اصطلاح الفقهاء هو: الحكم المطابق للواقع على الأقوال والعقائد والأديان

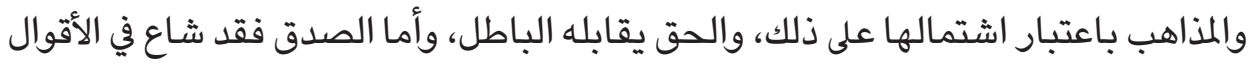

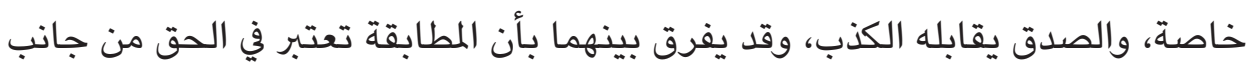
الواقع، وفي الصدق من جانب الحكم. وأيضاً قال الفقهاء أن الحق هو: البن الحكم الثابت شرعاً، وقد يطلق الحق على المال

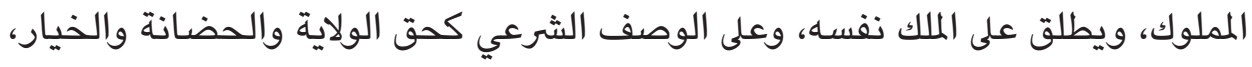

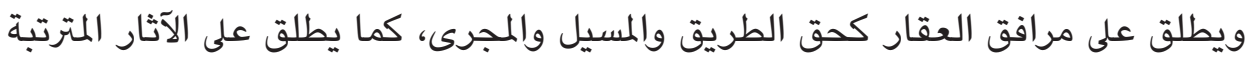
على العقود كالالتزام بتسليم المبيع أو الثمن.

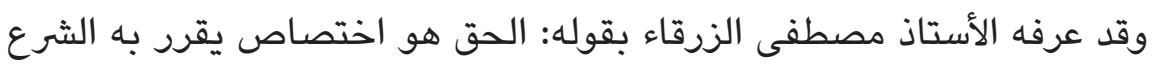
سلطةً أو تكليفاً، وهذا يشمل الحقوق الدينية كحق الله على عباده من صلاة وصيام 
ونحوهما، والحقوق المدنية كحق التملك، والحقوق الأدبية كحق الوالد على ولده، وحق

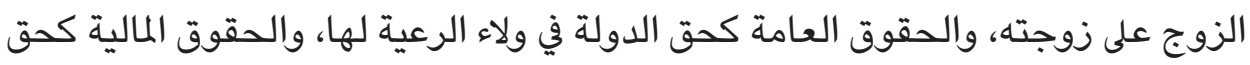

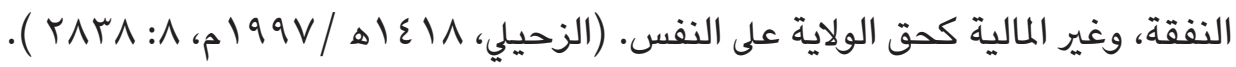

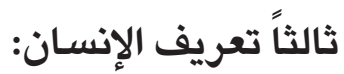
الإنسان في اللغة: من الإنس، والإنس خلاف الجن الجن، وهو البشر، والواحد إنسي وأنسي،

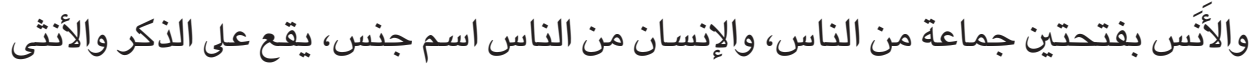

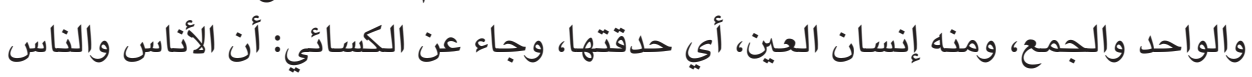

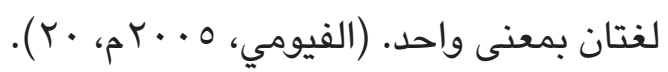

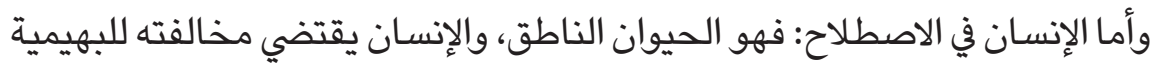
ويدل على ذلك اشتقاق الإنسان من النسيان، والنسيان لا يكون إلا بعد العلم، والإنسان الإنسان

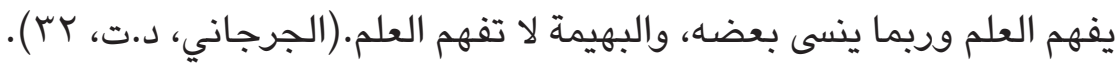

\section{المطلب الثاني: مبادرة الإسلام في المناداة بحقوق الإنسان:}

إن الدين الإسلامي له فضل السبق في المناداة بحقوق الإنسان وقد شهد بذلك العقل

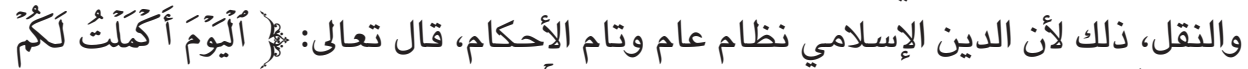

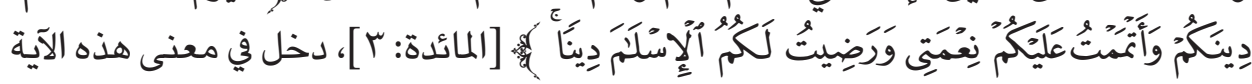

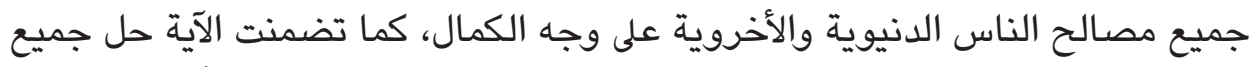

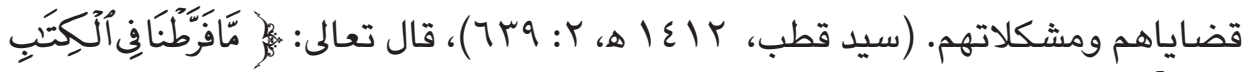

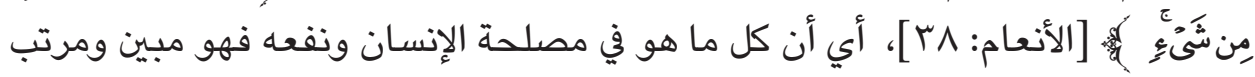

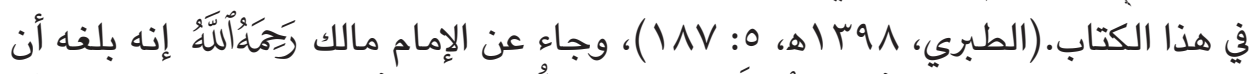

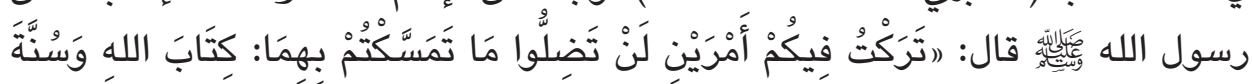

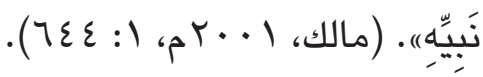

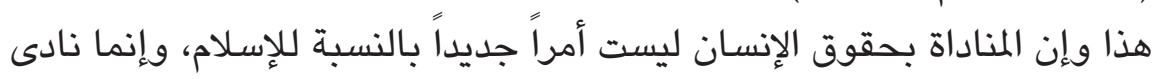

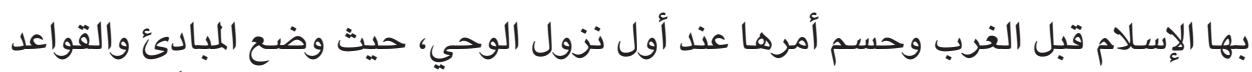

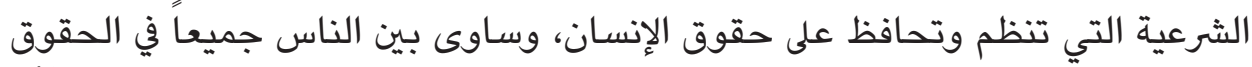

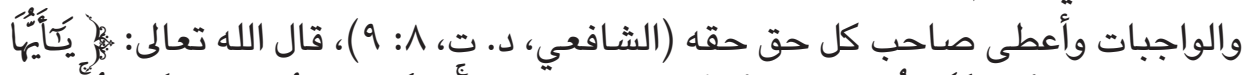

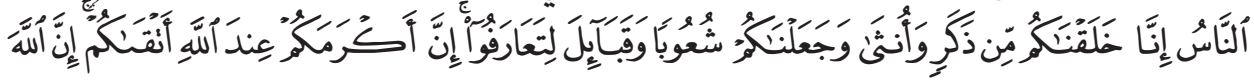




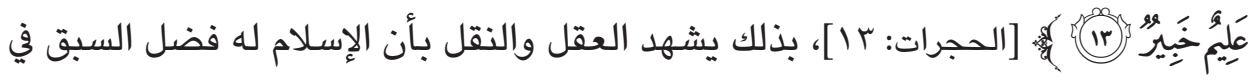

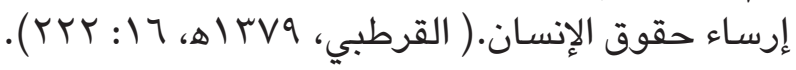
كما يشهد الواقع بسبق وتفوق التشريع الإسلامي على غيره وخلوده وصلان وصلاحهـ لكل

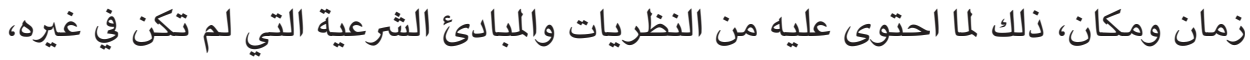

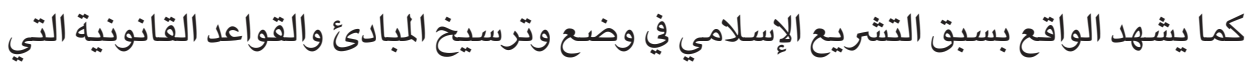

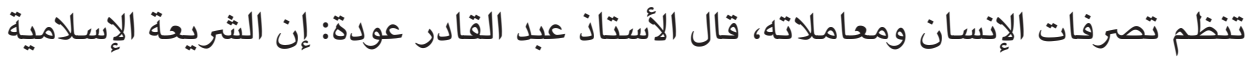

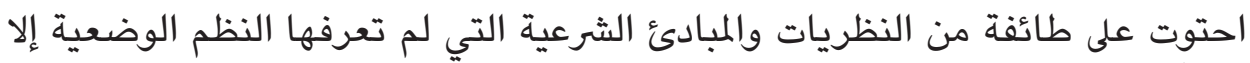
أخيراً، وقد تميزت عن القوانين الوضعية بميزات كثيرة منها:

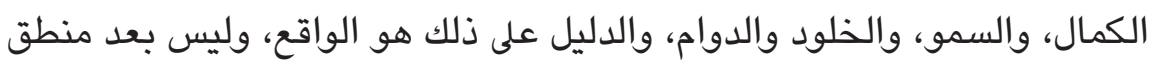

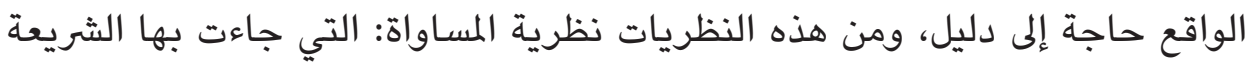
الإسلامية من وقت نزولها، بنصوص صريحة تقررها وتفرضها ويصفة مطلقة بلا قيود

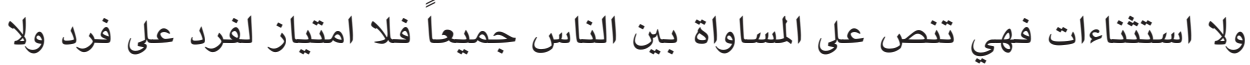

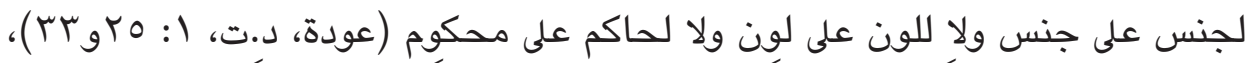

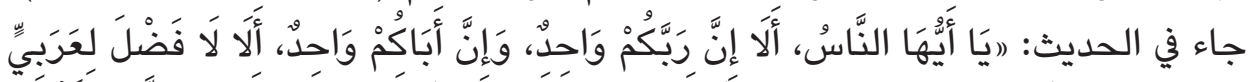

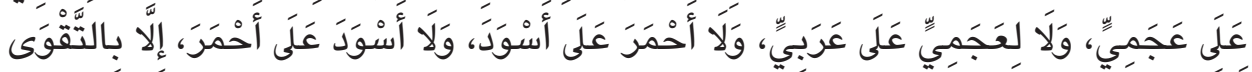

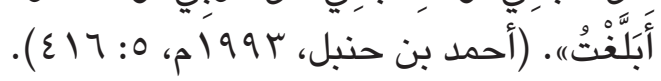

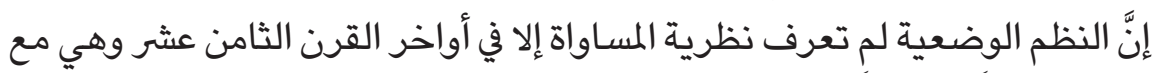

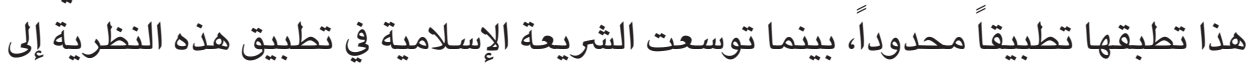

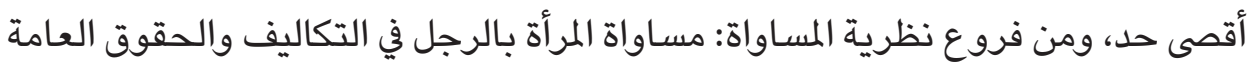

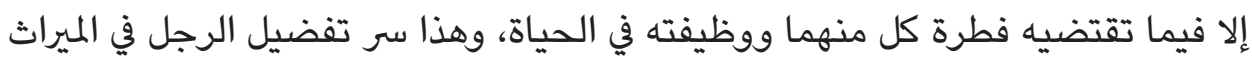

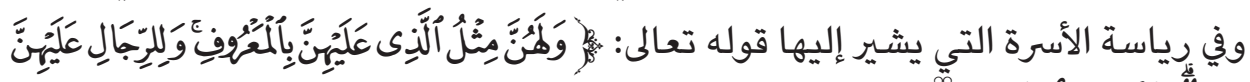

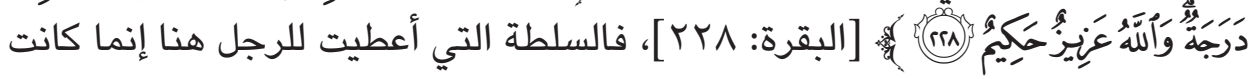

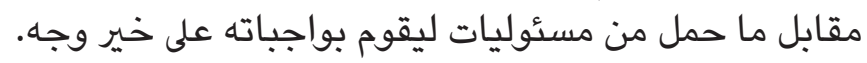

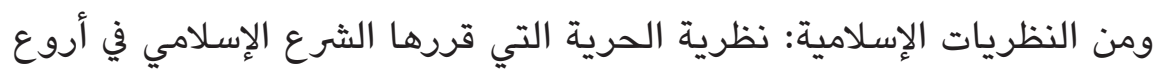

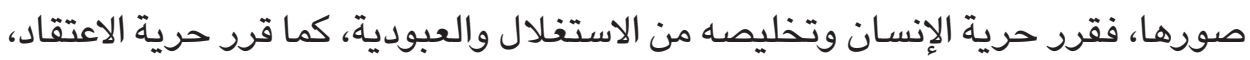

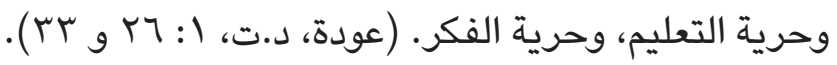




\section{المطلب الثالث: أصالت التشريع الإسلامي وثباته:}

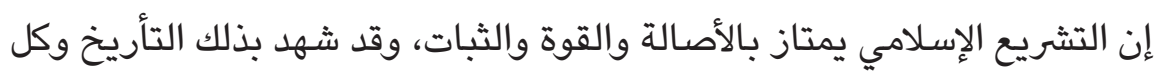

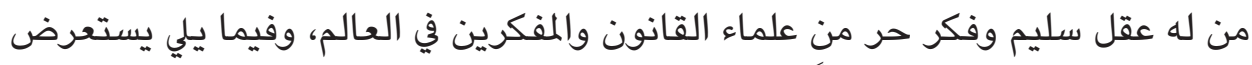

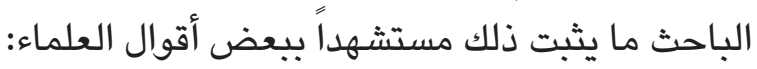

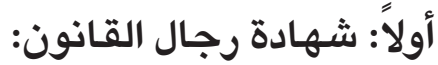

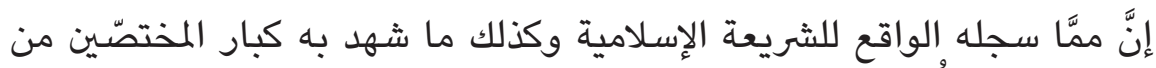
رجال القانون، الذين أتيح لهم الإطلاع على بعض كنوز الشريعة الإسلامية وفقهها الغني

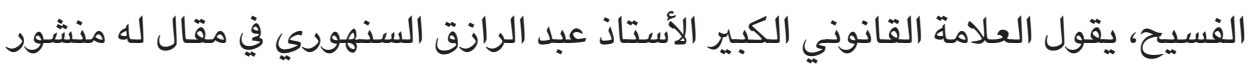

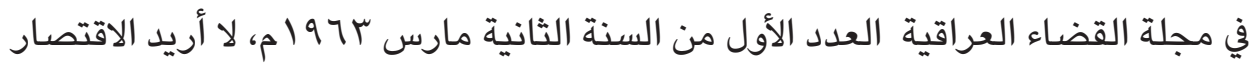

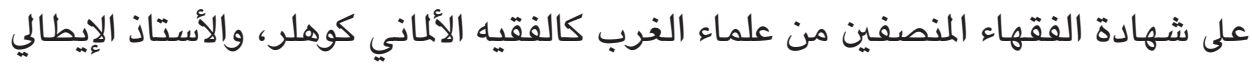
دليفيشيو، والعميد الأمريكي ويكمور وكثيرين غيرهم ممن يشهدون بما المهاء انطوت عليه

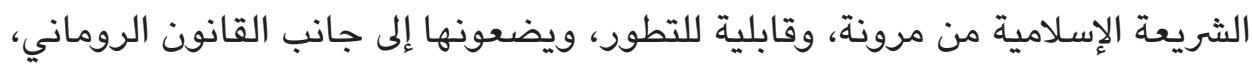

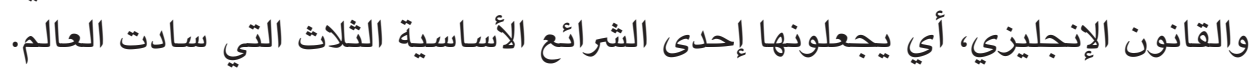

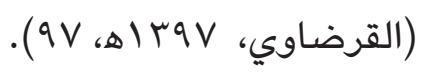

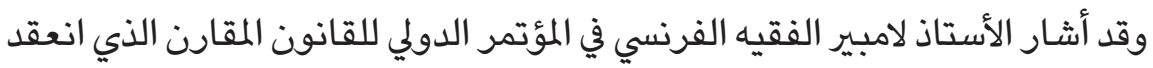

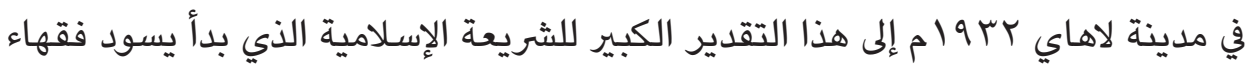

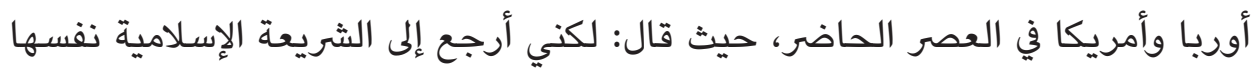

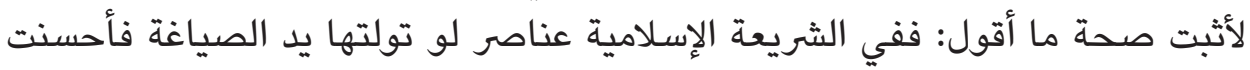

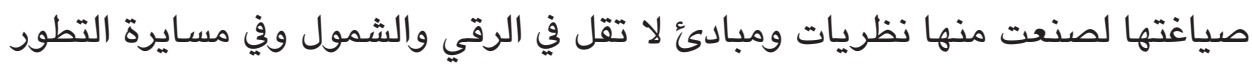
عن أخطر النظريات الفقهية التي نتلقاها اليوم عن الفقه الغربي الحديث لاعيث (الأمم المتحدة، الإعلان العالمي لحقوق الانسان). ويقول الدكتور علي بدوي عميد كلية الحقوق بمصر سابقاً بعد مقارنة بين الشريعة الشان

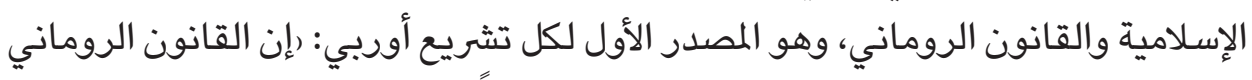

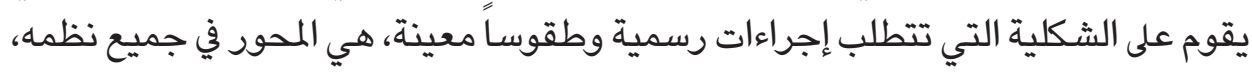

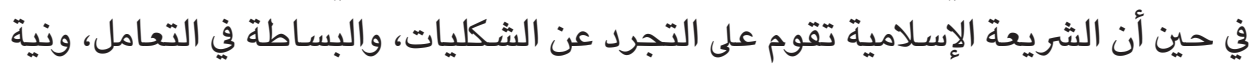

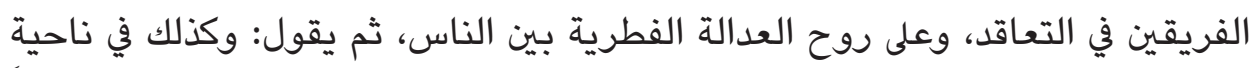

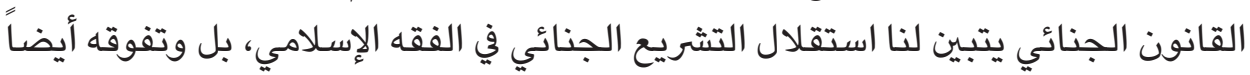
على غيره من التشريعات القديمة والحديثة). (الأمم المتحدة، الإعلان العالمي لحقوق الإني الإنساني). 


\section{ثانياً: شهادة المنصفين من الغريبين:}

كل هذه الشهادات المؤيدة للشريعة الإسلامية ليست من رجال الأزهر الشريف، ولا من أساتذة الفقه في الجامعات الإسلامية، وإنما هي شهادات الفوات من كبار رجال القال القانون

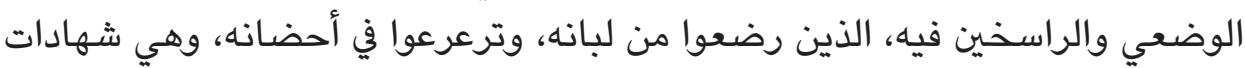
معللة تحمل في عباراتها براهين صدقها. يقول الدكتور إيزكو إنساباتو: (إن الشريعة الإسلامية تفوق في كثير من بحوثها الشرائع الأوروبية، بل هي التي تعطي للعالم أرسخ الشرائع ثباتاً).

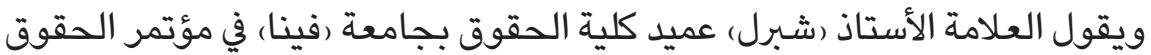

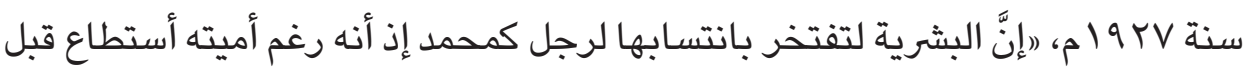

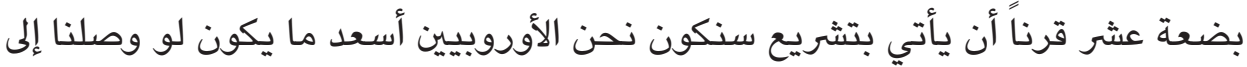

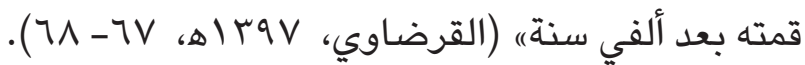

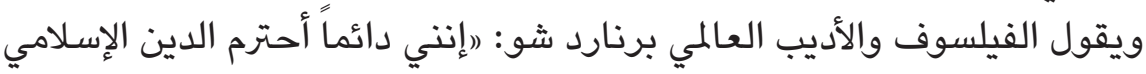
غاية الاحترام لما فيه من الحيوية، فهو وحده الدين الذي يظهر لي أنها فئه (يملك القوة المحولة)

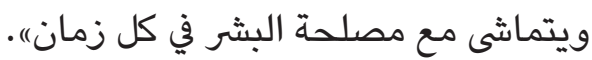
ويقول المؤرخ الإنجليزي (ويليز) في كتابه (ملامح تأريخ الإنسانية) (إن أورويا مدينة للإسلام بالجانب الأكبر من قوانينها الإدارية والتجاريةه).

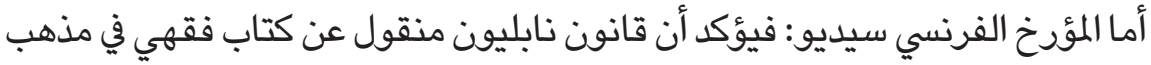
الإمام مالك هو: شرح الدردير على متن خليل (فهرس حقوق الإنسان في الدول العربية).

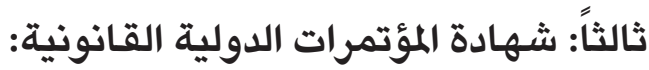

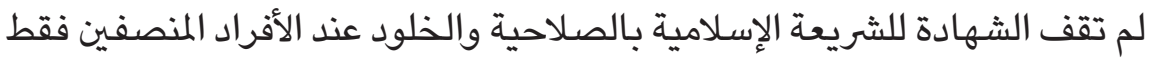
من الغربيين، بل تجاوزت هذا النطاق إلى دائرة أرحب وأشمل هي دائرة المؤتمرات الدولية

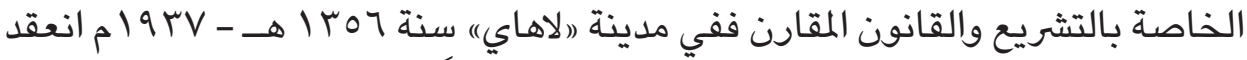

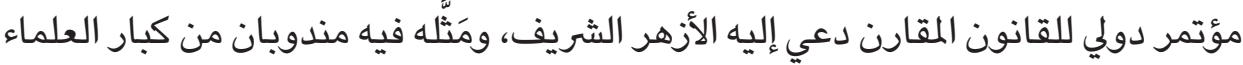
وقد حاضرا فيه عن (المسئولية المدنية والجنائية في الشريعة الإسلامية) وعن استقلال

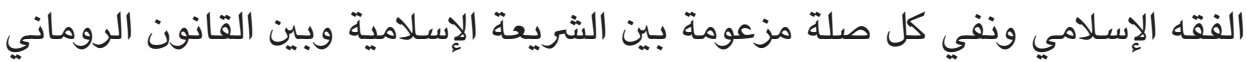

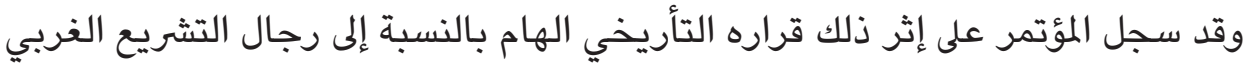
وقد جاء فيه ما يلي: اعتبار الشريعة الإسلامية مصدراً من مصادر التشريع العام. 


\section{إن الشريعة الإسلامية حية وقابلة للتطور. \\ الشريعة الإسلامية شرع قائم بذاته ليس مأخوذاً عن غيرها}

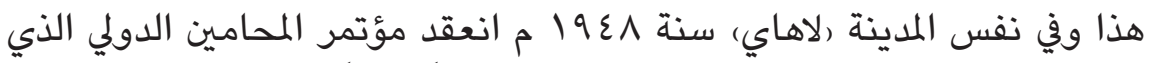

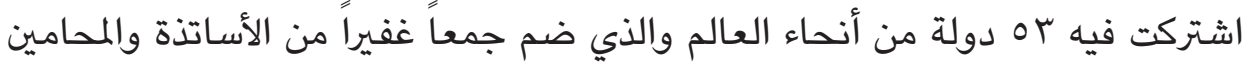

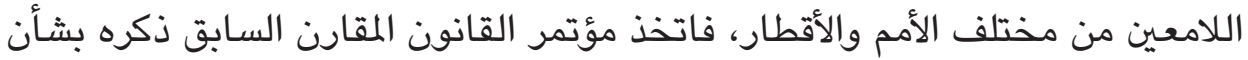

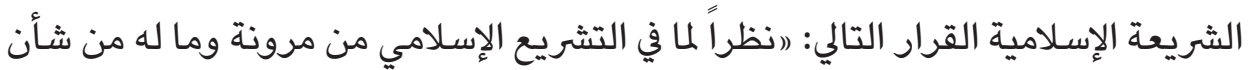

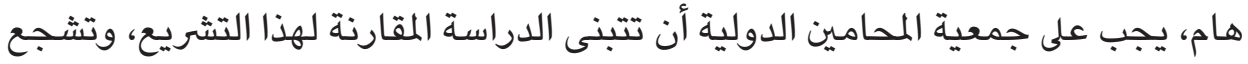

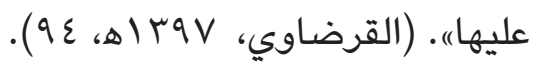

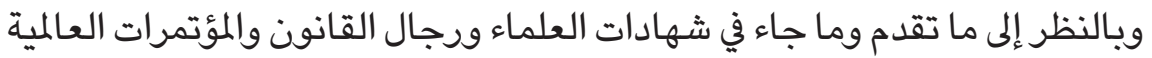
المختصة، كل ذلك يؤكد لنا أن في تلك المفاهيم والآراء أقوى شهاء فيادة على أصادات أصالة التشريع

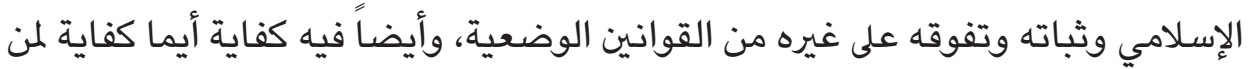

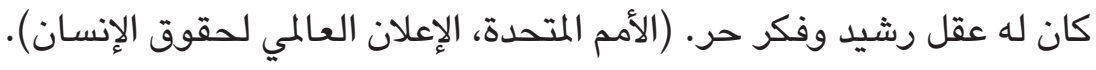
المطلب الرابع: مظاهر تفوق التشريع الإسلامي على غيره:

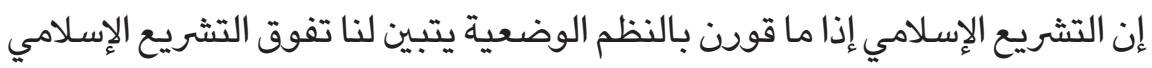

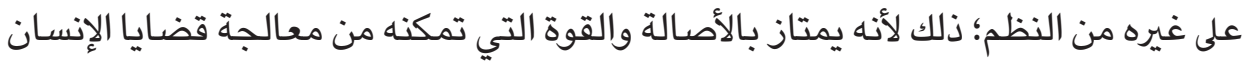

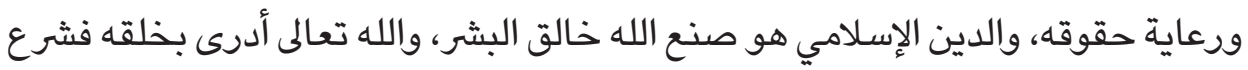

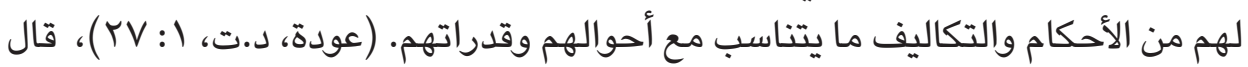
تعالى:

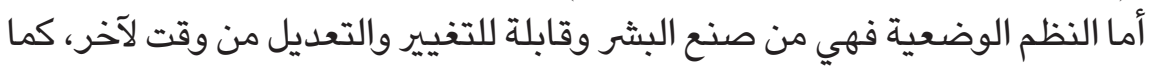

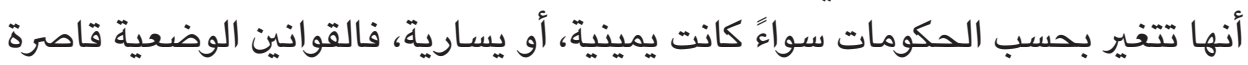
ولا تتناغم مع أحوال الناس وظروفهم ولا تفي بحاجاتهم.

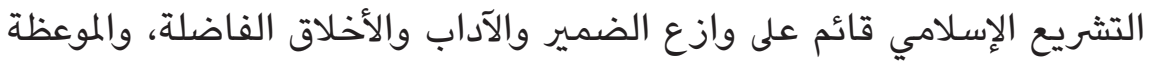

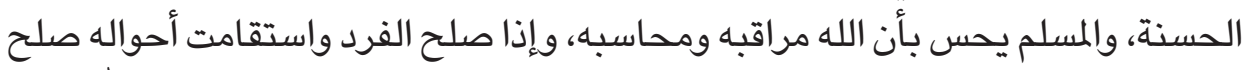

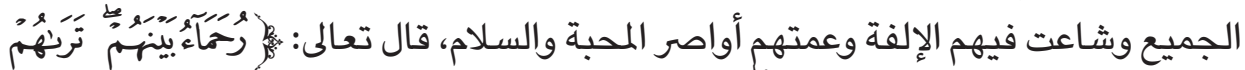

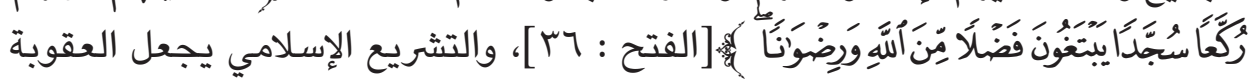

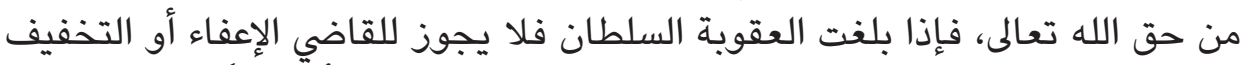

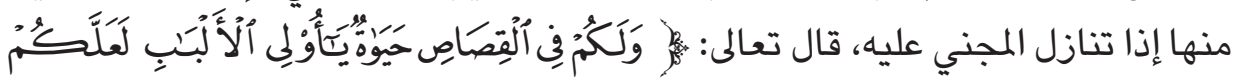




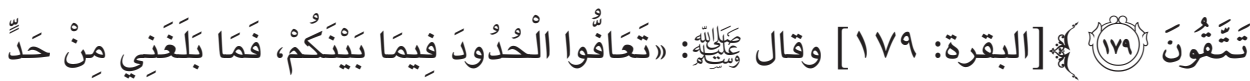

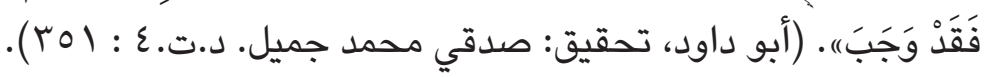

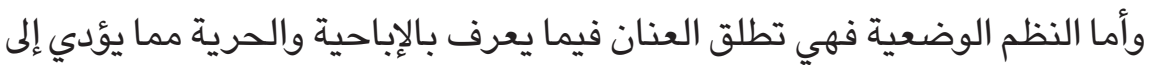

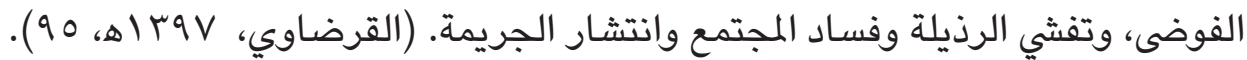

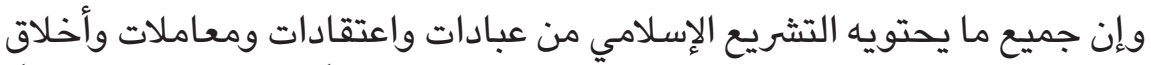

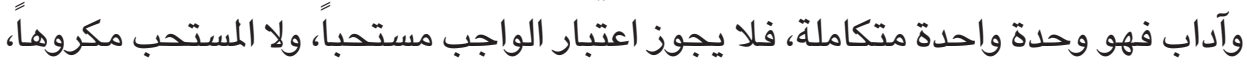

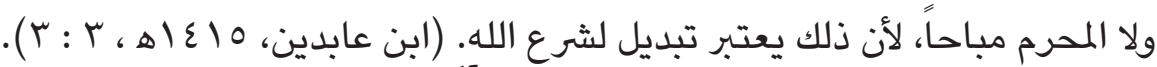
تال تعالى:

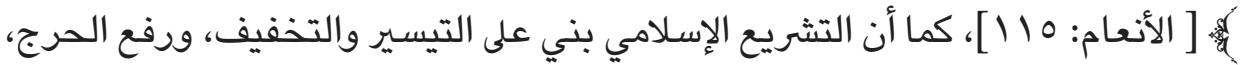

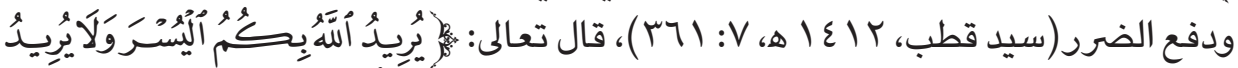

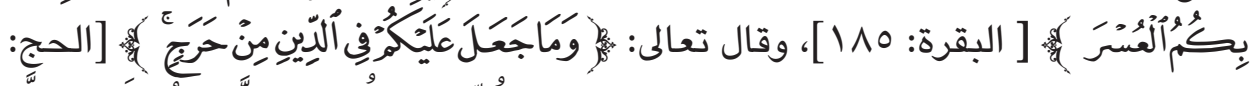
[V1

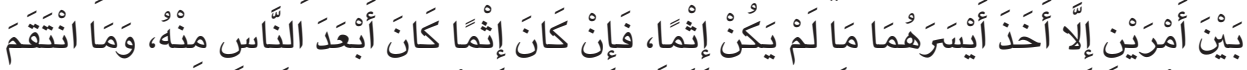

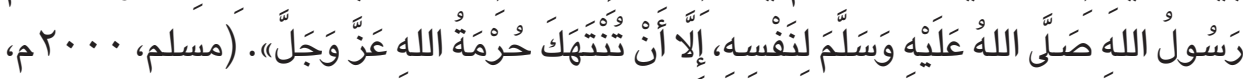

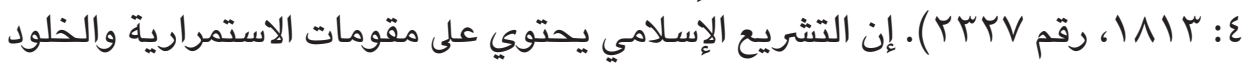

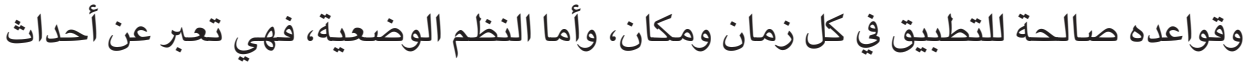

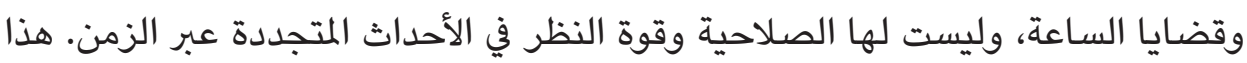

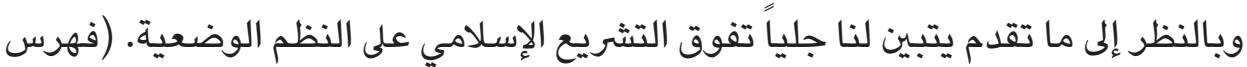
حقوق الإنسان في الدول العربية).

\section{المبحث الثاني: عنايت الإسلام بحقوق الإنسان المطلب الأول: مميزات حقوق الإنسان في الإسلام:}

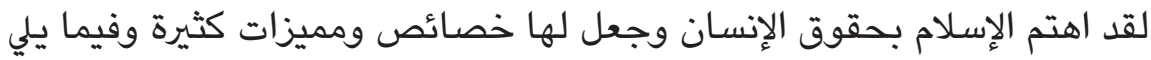
نورد بعض ما تميزت به تلك الحقوق:

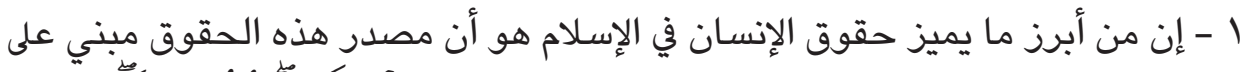

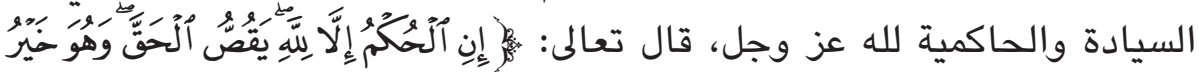

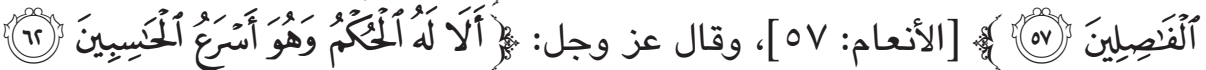

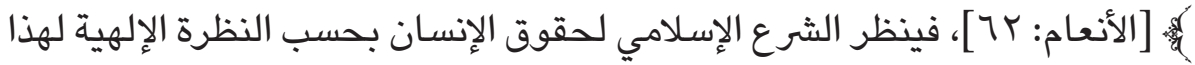




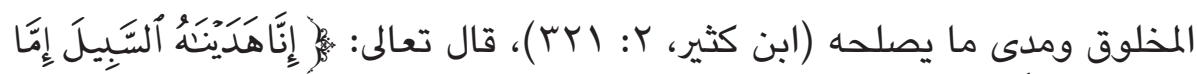

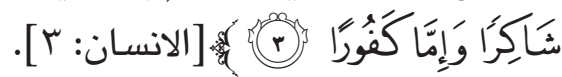

Y- الثبات: فلا تتفير هذه الحقوق بتغير الزمان ولا بتبدل المكان، وتتضح هذه الميزة

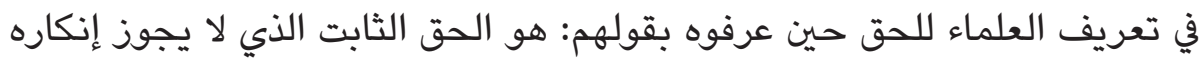

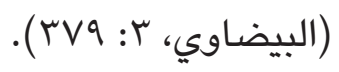

r- مراعاة انطلاق الحقوق من مقام الإحسان، فالحقوق في الإسلام تنبع من المقام الذي يقوم

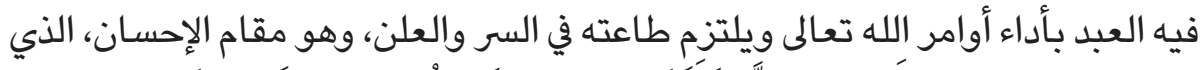

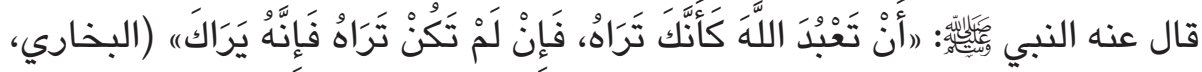

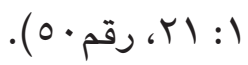

ع- الانسجام والتكامل بين حقوق الإنسان وطبيعة هذا الدين، فالإسلام لم يترك الحقوق

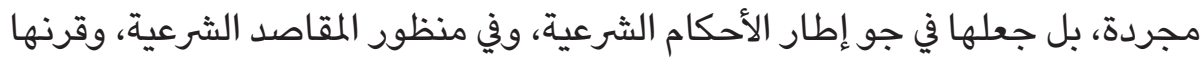

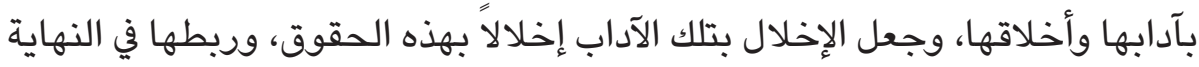

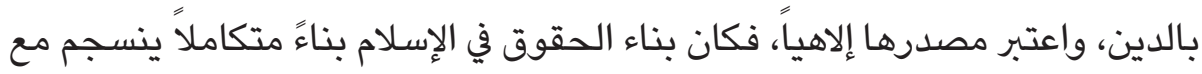
الطبيعة الربانية لهذا الدين.

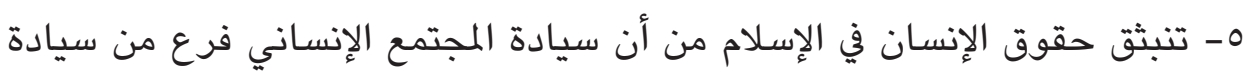
أفراده، وليس العكس كالحال في النظم الوضعية (الدسوقي،

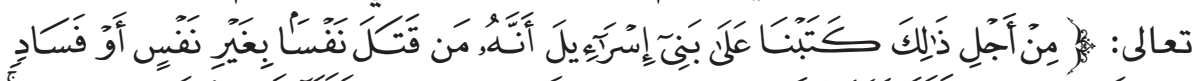

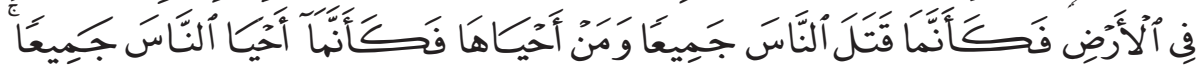

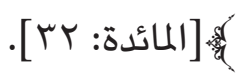

7- السبق الزمني للإسلام في تحقيق مبادئ حقوق الإنسان، إذ أن هذه الحقوق التي كفلها

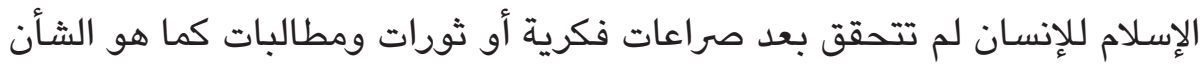

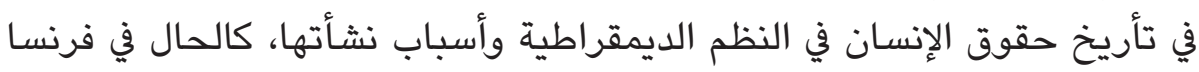

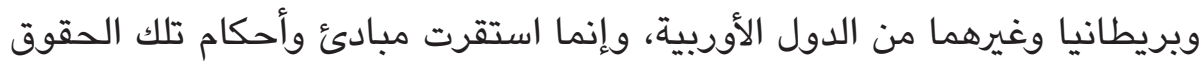

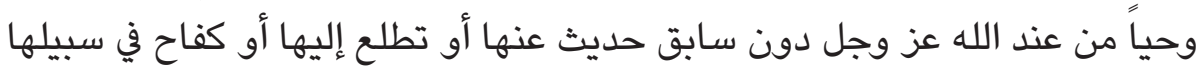

$$
\text { (فهرس حقوق الإنسان في الدول العربية). }
$$

V - إن حقوق الإنسان في الإسلام حقوق واقعية ومرتبطة بحياة جميع الناس، وتلمس

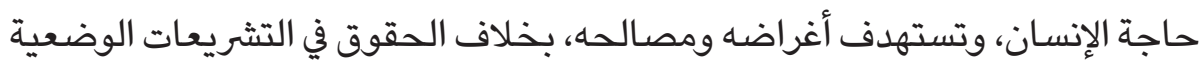

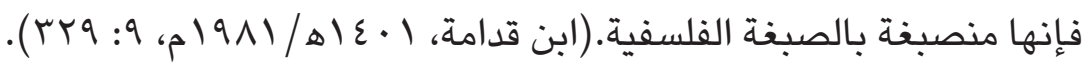




\section{المطلب الثاني: بعض الحقوق التي انفرد بها الإسلام}

إن الدين الإسلامي قد نص على الأحكام والقواعد التي تثبت وتؤمن حقوق الإنمان الإنسان

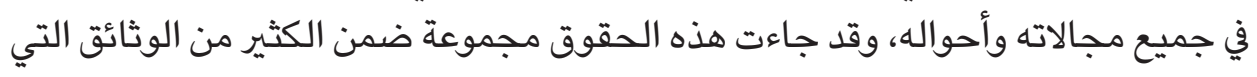
صدرت على المستوى الإسلامي في حقوق الإنسان.

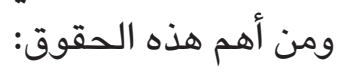

حق الفضل والكرامة المكتسب من العمل والعقيدة.

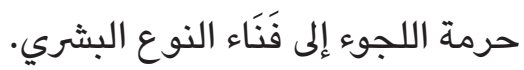

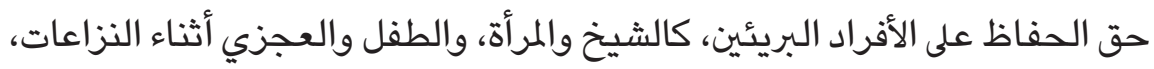
ومداواة الجرحى، والحفاظ على الأسرى، وحرمة التمثيل بالقتلى. حق الإنسانية في عدم إتلاف الزروع، وتخريب المباني المدنية أثناء النزاعات.

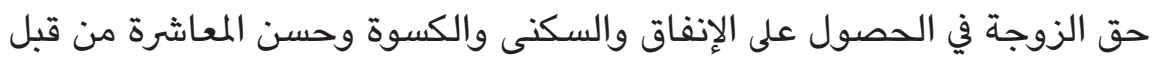
الزوج·

حق الأسرة بإيوائها والنفقة عليها وتعليم أفرادها، ورعاية الجنين وإطعامه، وعلاجه إذا مرض، وتوريثه والمحافظة عليه.

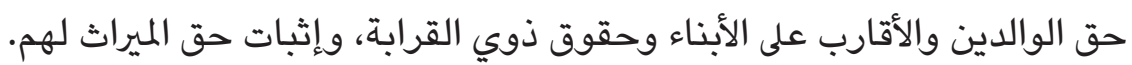

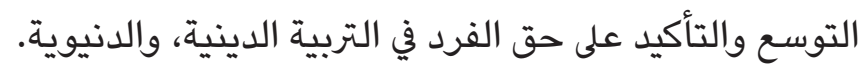
حق الإنسان في التحرر من قيود الرق والاستعمار. حق الكسب المشروع والبيع الحلال، والتعامل بين أفراد المجتمع. حق الدعوة إلى الخير والأمر بالمعروف واليح النهي عن المنكر.

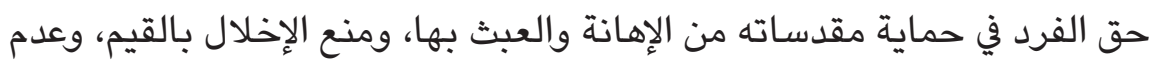

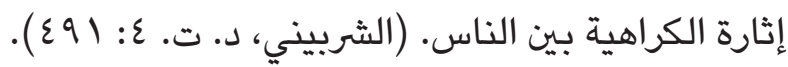

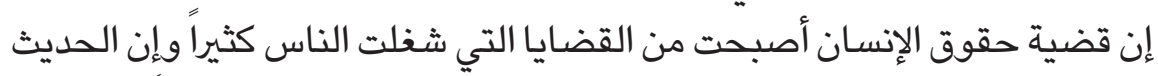

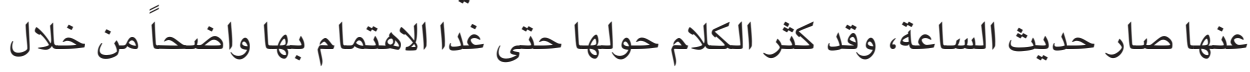

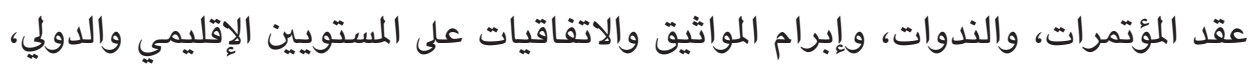

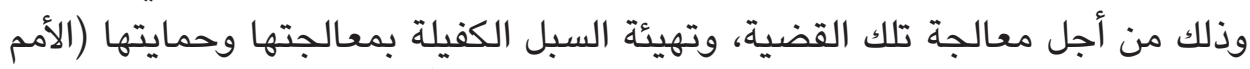

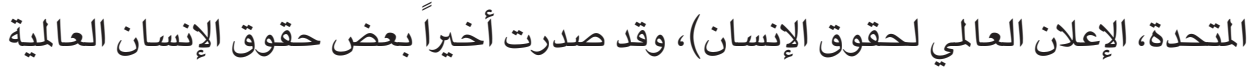

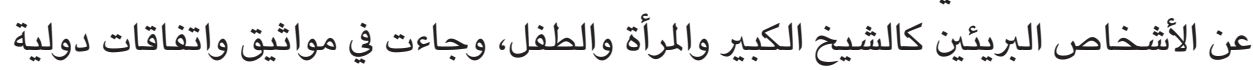


لاحقة، مثل: معاهدة جنيف، والاتفاقية الدولية بشأن الحقوق الاقتصادية، والاجتماعية،

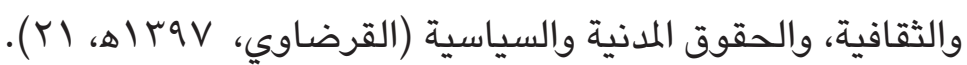
ونجد أن الإسلام قد اهتم بقضية حقوق الإنسان منذ أول ظهوره، ووضع المبادئ

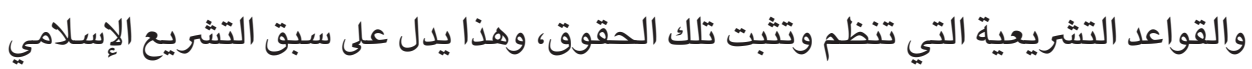
على غيره في إرساء مبادئ حقوق الإنسان (فهرس حقوق الإنسان في الدول العربية).

\section{المبحث الثالث: الإسلام يحافظ على الانسان ويمنع استغلاله المطلب الأول: الإسلام يحرم الرق ويغلق أبوابه}

يعتبر الرق من أكبر الهواجس التي تهدد الإنسان وتنتهك كرامته وتسلب حريتها

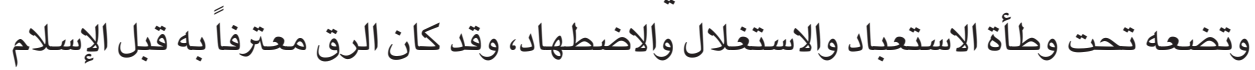

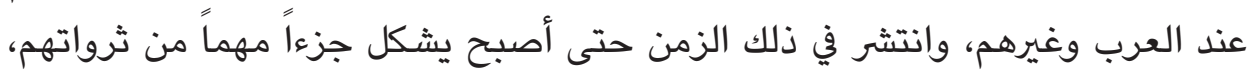

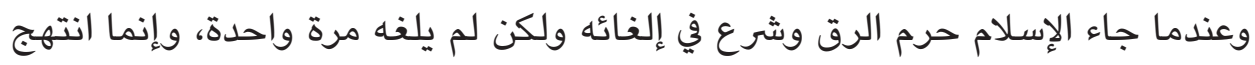

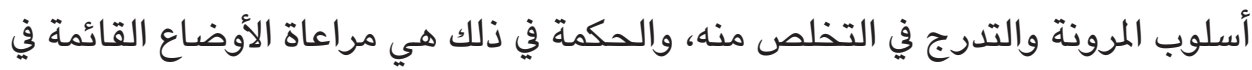

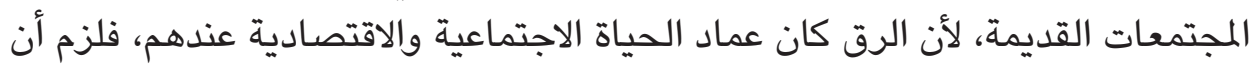

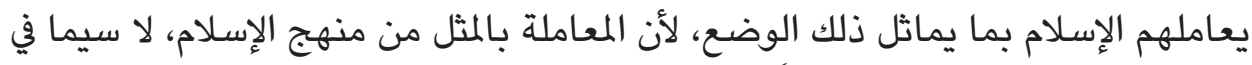

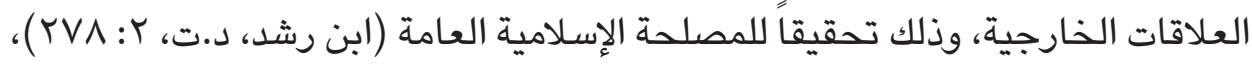

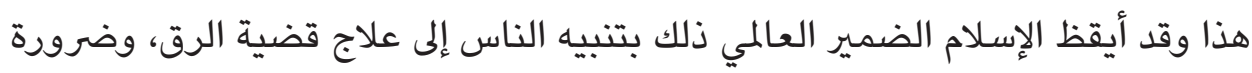

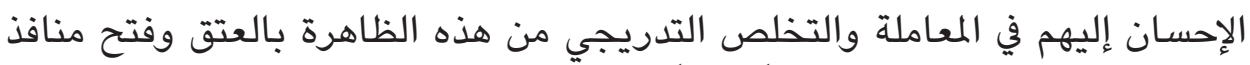

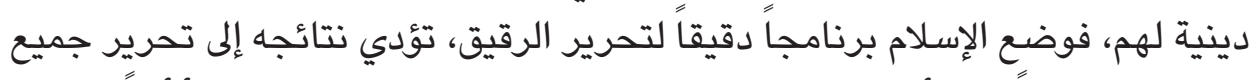

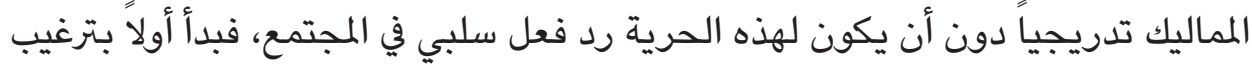

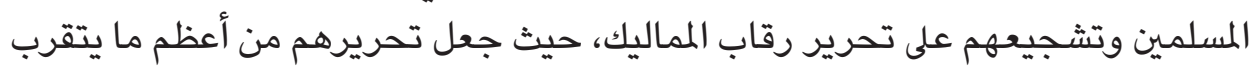

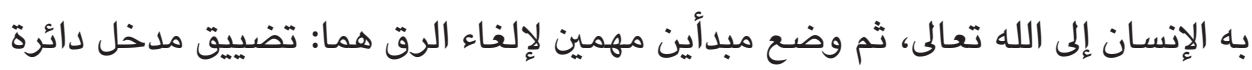

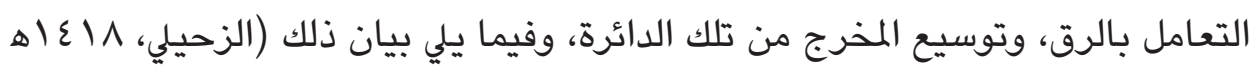

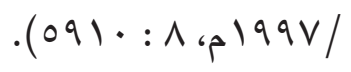

\section{أولاً: تضييق مدخل دائرة الرق}

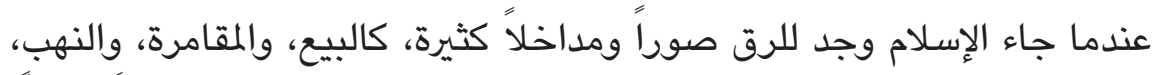

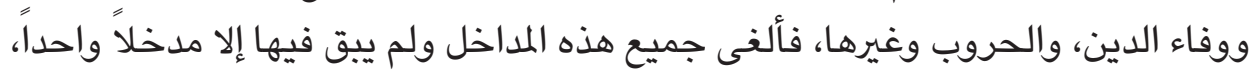

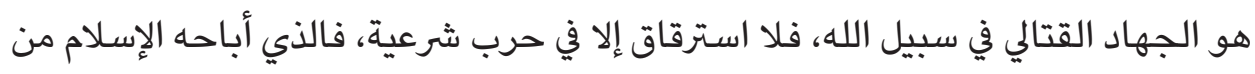


الرق هو مباح في نظم الأمم التي عاهدت على منع الرق، حيث إنَّ هذه الأمم تبيح الأسر

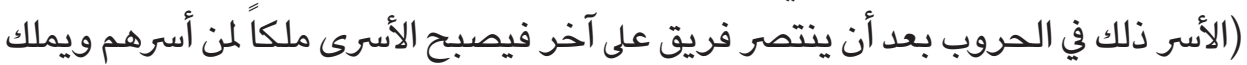

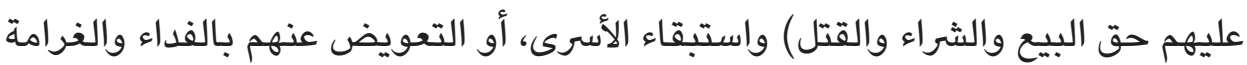

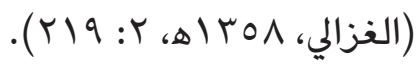

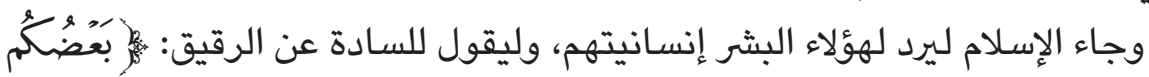

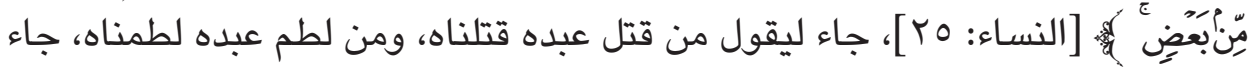

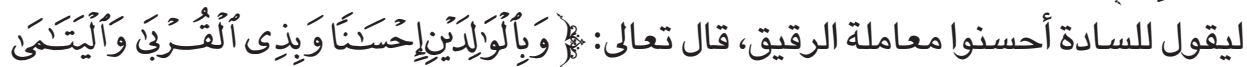

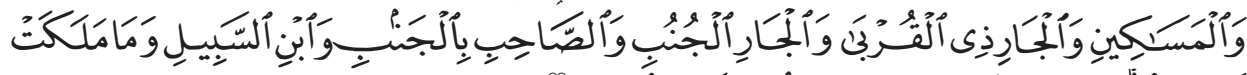

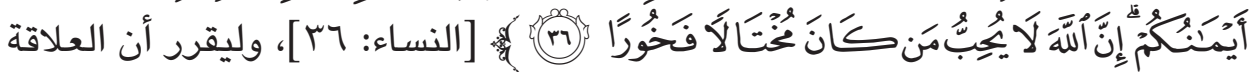

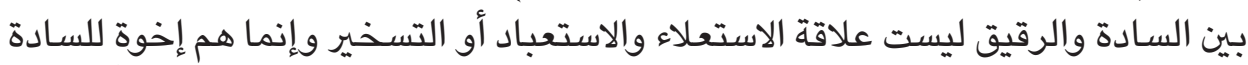

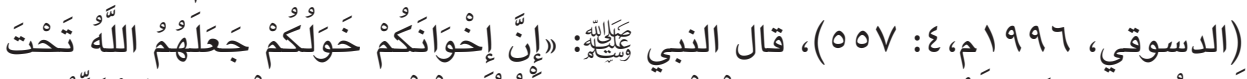

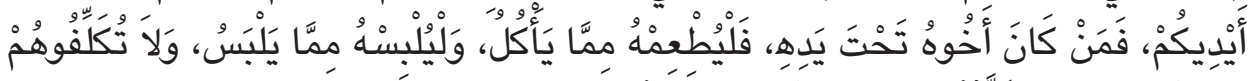

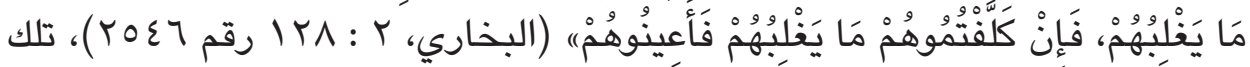

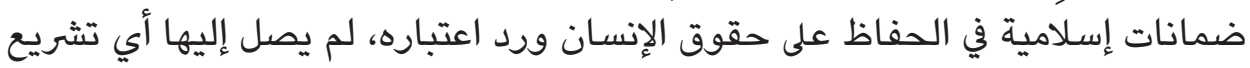

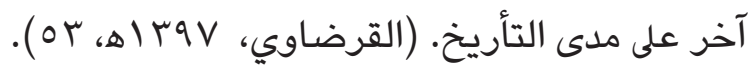
ثانياً: توسيع مخرج دائرة الرق الترخ

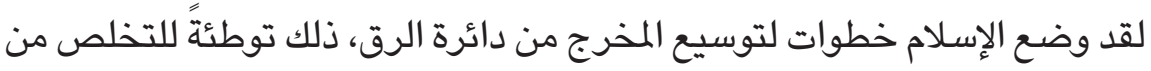
ظاهرة الرق واستعباد الإنسان، ومن تلك الخطوات شراء المماليك وإعتاقهم في سبيل الله:

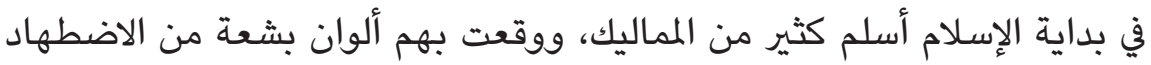

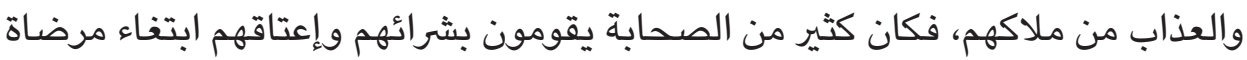

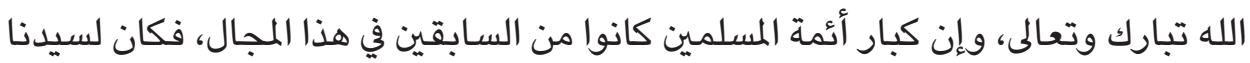

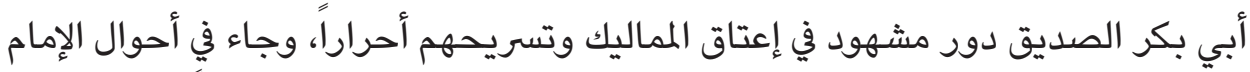

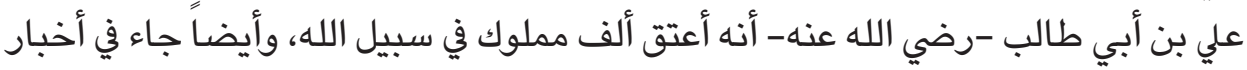

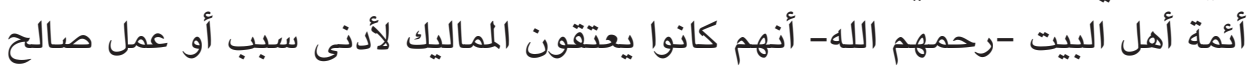

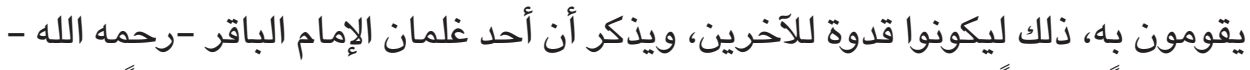

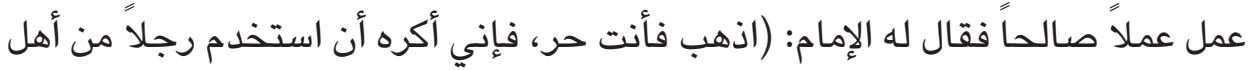

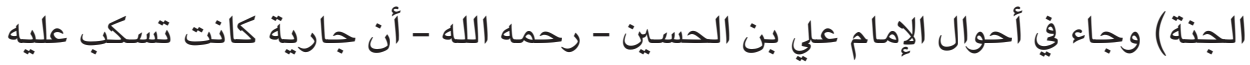

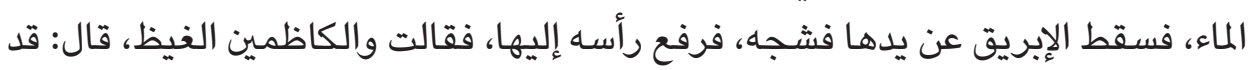


كظمت غيظي، قالت والعافين عن الناس، قال: عفا الله عنك، قالت والله يحب المحسنين،

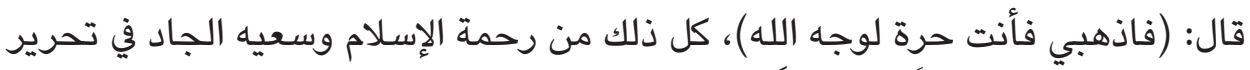

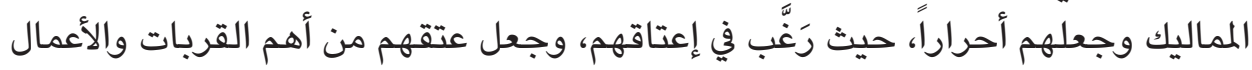

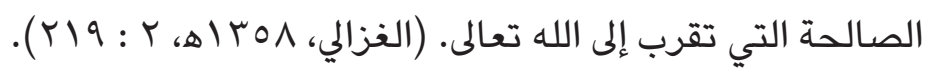
فيما تقدم علمنا أن صور استرقاق الإنسان واستعباده كانت كثيرة قبل بعثة النبي

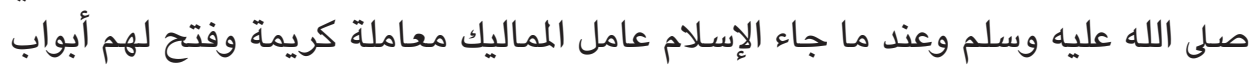

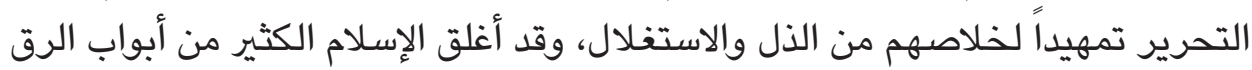

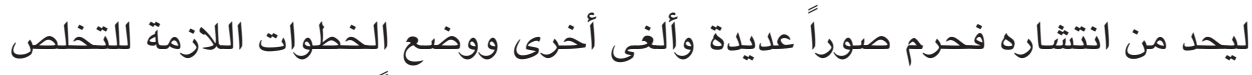

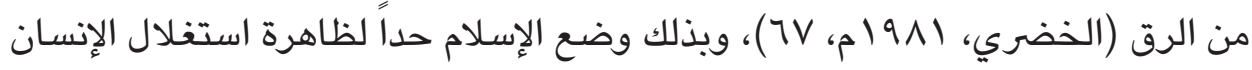
لأخيه الإنسان.

ومما لا شك فيه أن حقوق الإنسان لم توضع قط موضع التنفيذ في تأريخ البشرية

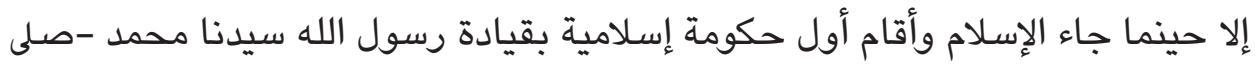
الله عليه وسلم- واستمرت منفذة ومطبقة للتشريعات الإسلامية عبر العصور إلى يومنا

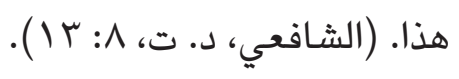

\section{المطلب الثاني: حكمت التدرج في إلغاء الرق}

لقد تدرج الإسلام في إلغاء نظام الرق لحكم وأسباب منها:

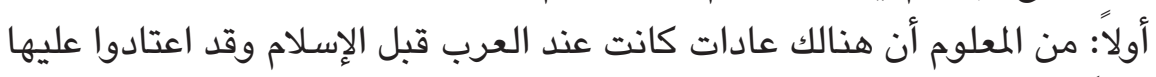

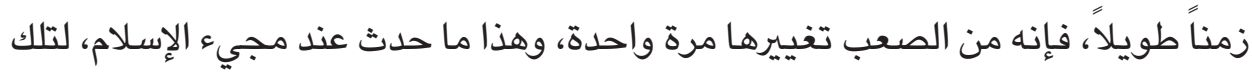
الأسباب فقد تدرج الإسلام في عملية إلغاء الرق.

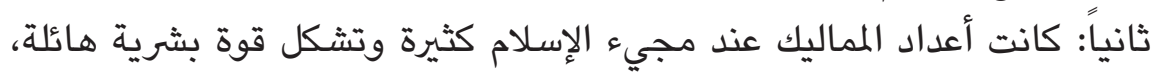

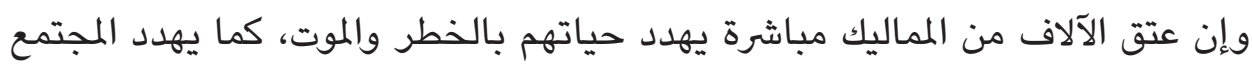

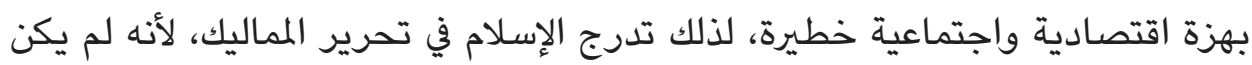

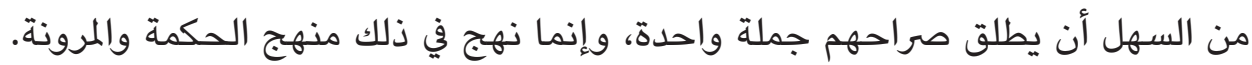

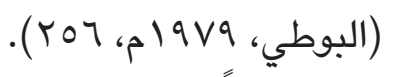

ثالثاً: إن الإسلام لم يكن المبتدع للرق مطلقاً، بل كان الرقان الرق موجوداً في أنحاء العالم

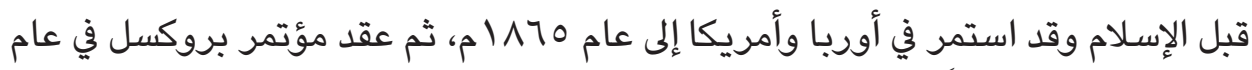

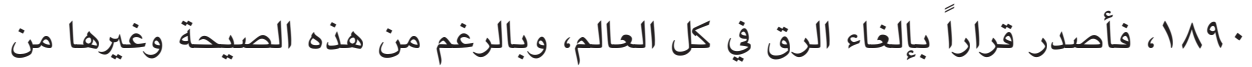

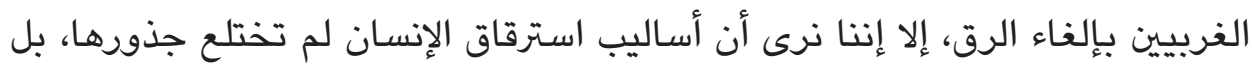


إنها تحورت إلى صور أخرى أخطر وأكثر رعباً، إذ إنها أخذت شكل استعمار الشعوب، ألفاء

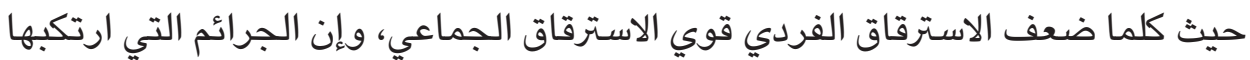

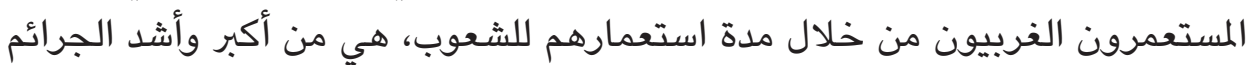

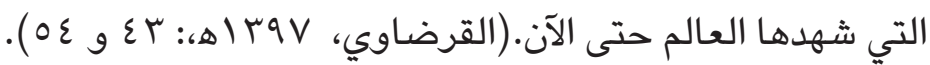

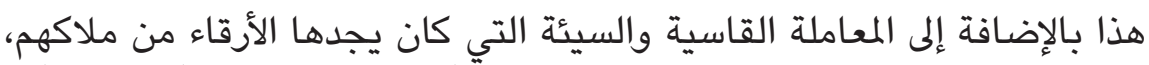

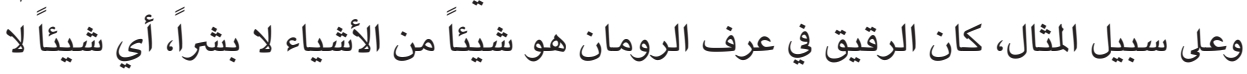
حقوق له البتة، فكان للسيد مطلق الحق في تسخيره واستعباده، وبيعه وشرائه، فقد كانت لهم أسواق لبيع وشراء الرقيق يقف فيها المملوك والأمة، يقف كسلعة تباع وتشترى ناست ناهيك

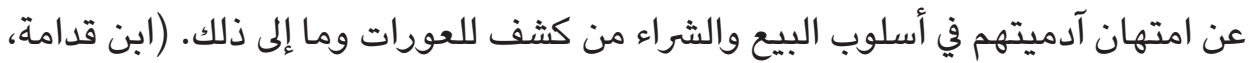

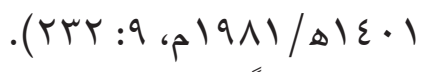

رابعاً: حينئذٍ جاء الإسلام وقرر إلغاء الرق، وحرم استخلال الإنسان لأخيه الإنسان،

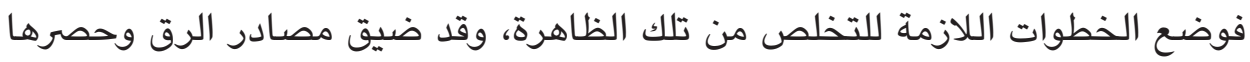

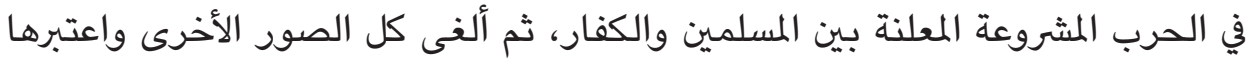

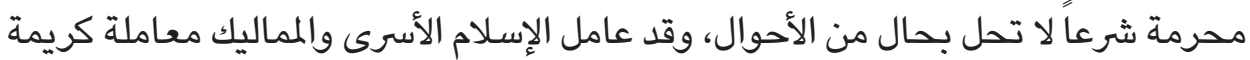

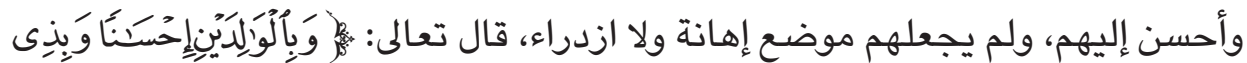

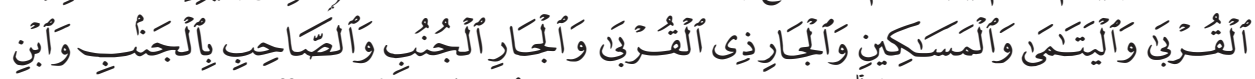

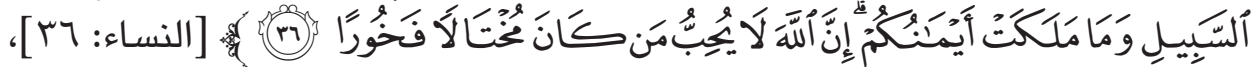

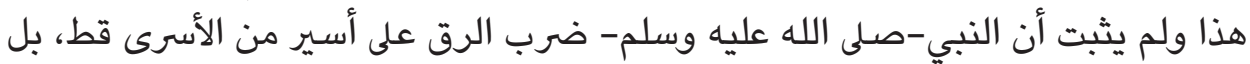

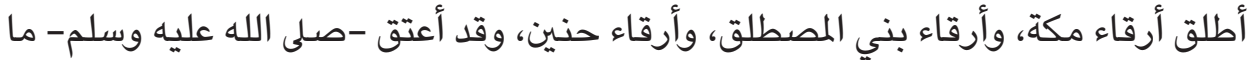

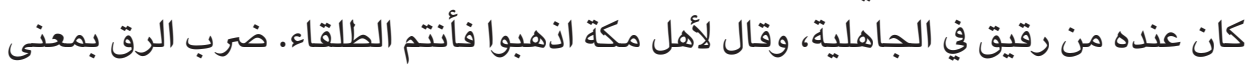

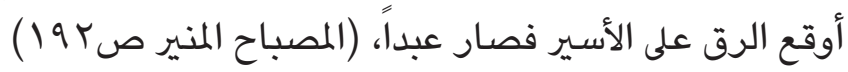

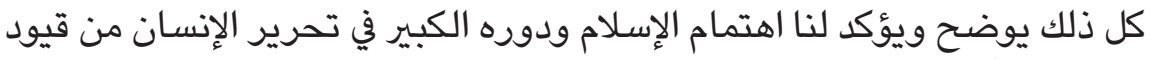
العبودية، إذ أنه أولاً ضيق مداخل الاسترقاق، ورغب في في عتق المماليك وجعله من أعظم القربات

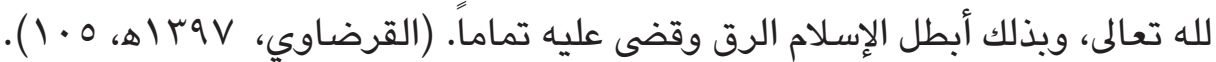
المطلب الثالث: استفادة الغرب من الحضارة الإسلامية:

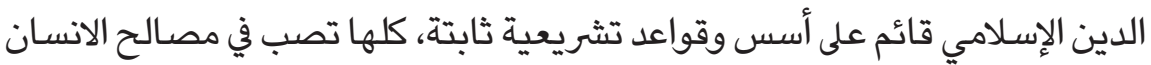

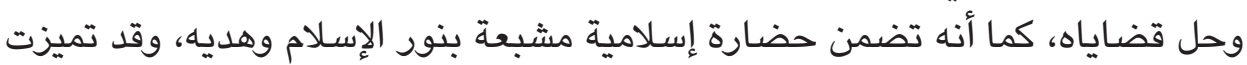
هذه الحضارة بالقوة والصلاحية مما جعلها تنتشر في كل أنحاء العالم، ويالرغم من كل الصامل 
ذلك نجد أن أهل الغرب يشككون في مبادئ التشريع الإسلامي ويتهمون المسلمين بالركود

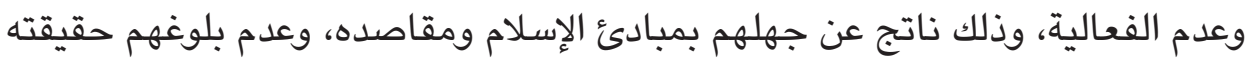

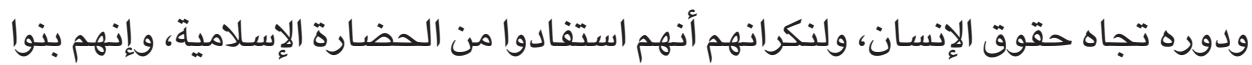

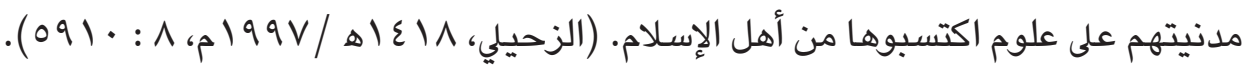
هذا وإن ما أصاب أهل الإسلام من غفلة وعدم إعلى العمال الرأي والاجتهاد على ضلى ضوء

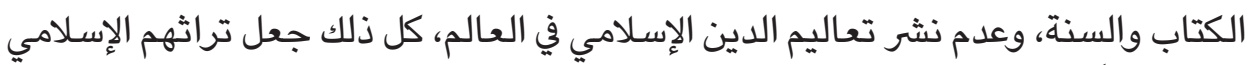

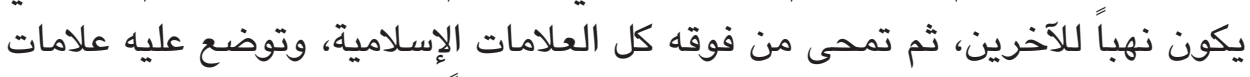

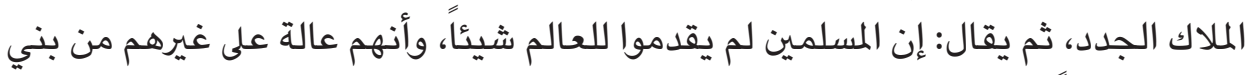

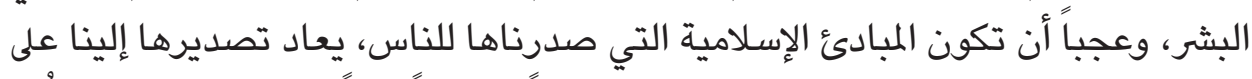
أنها من كشف الإنسان وابتكاره، ونحن نملك تراثاً إسلامياً غنياً بالمبادئ الرانياً الرفيعة والمُثل

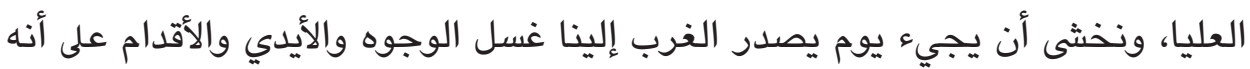

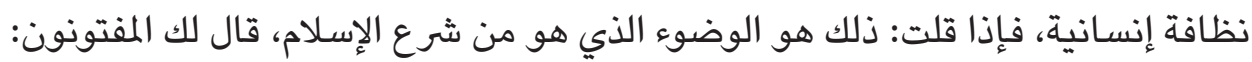

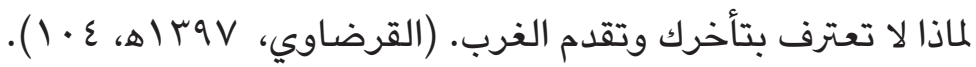

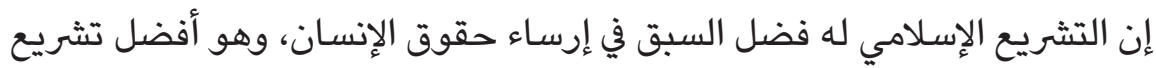

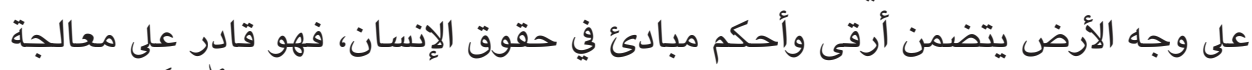

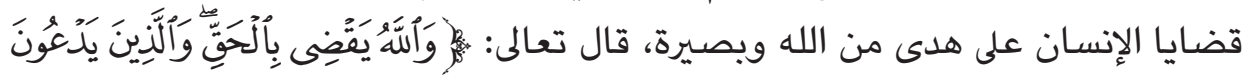

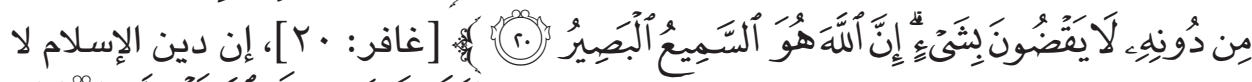

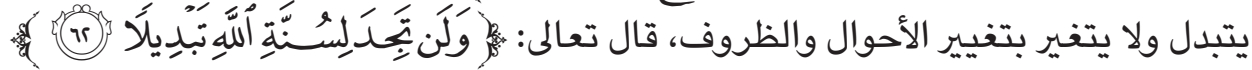
[الأحزاب: Y7 ]، كما أن مبادئ حقوق الإنسان في التشريع الإسلامي تشكل منهجية كاملة

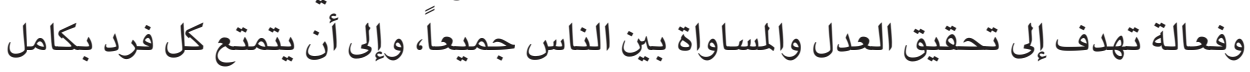

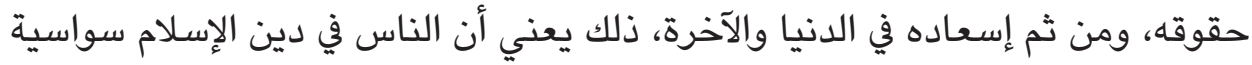

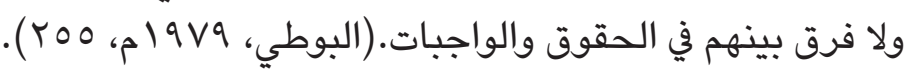

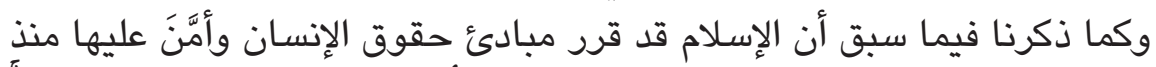

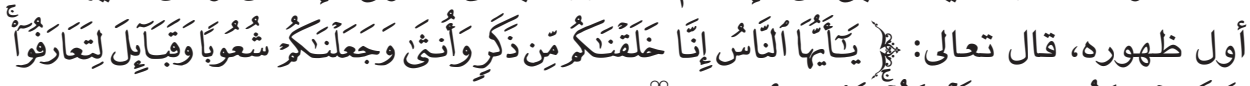

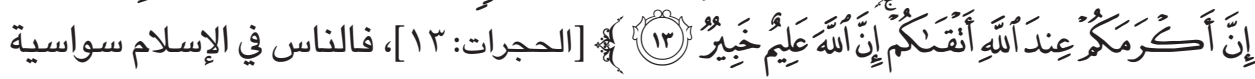

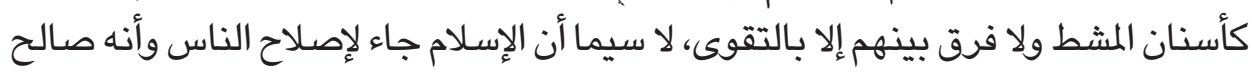

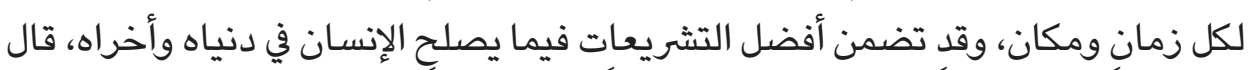

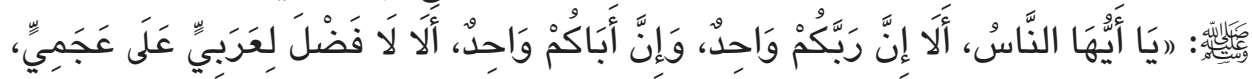




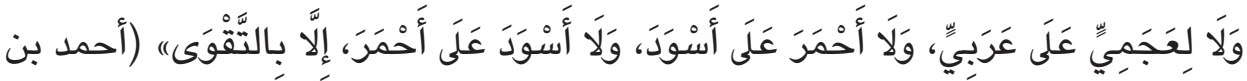

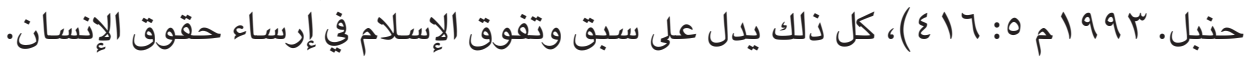

$$
\text { (القرضاوي، التول. }
$$

هذا وأن التأريخ يشهد بأن التشريع الإسلامي قد استطاع أن يعالج كل الوقائع والمشكلات عبر مراحل تأريخية مختلفة وفي بيئات اجتماعية متعددة، ذلك الكارئ لما اشتملت

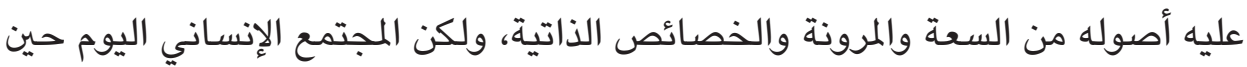

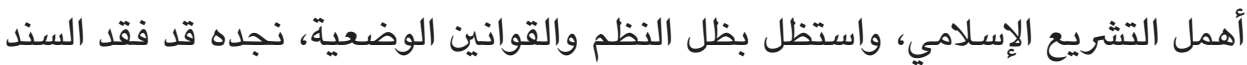

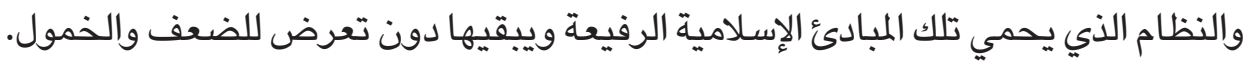
(/http:/ /islamonline.net) إن المطلوب من المسلمين الرجوع إلى دينهم الحنيف والمحافظة على تراثهم الإسلامي

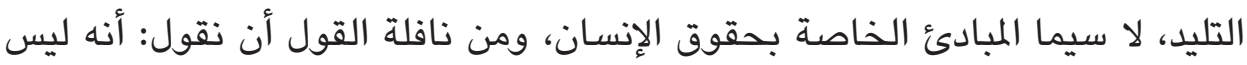
ثمة وسيلة أفضل من تمسكنا نحن المسلمين بتعاليم ديننا الإسلامي، وأن نقوم بتطبيق الماني

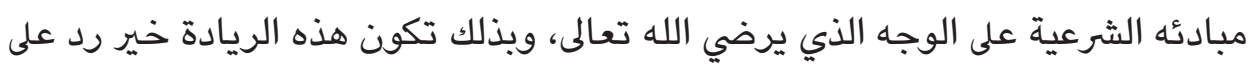

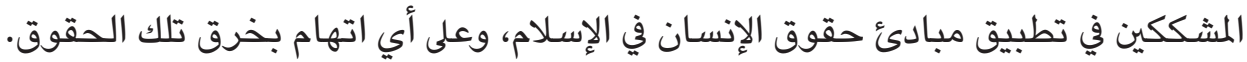

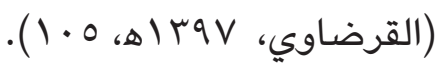

الخاتمت:

بهذا نصل إلى ختام هذا البحث الذي دارت محاوره حول قضية حقوق الإنسان، وكما

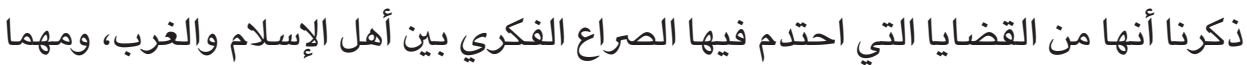

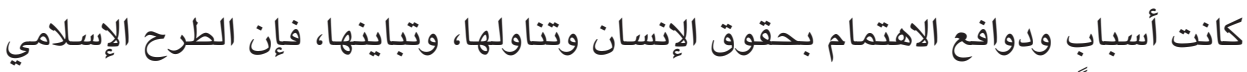

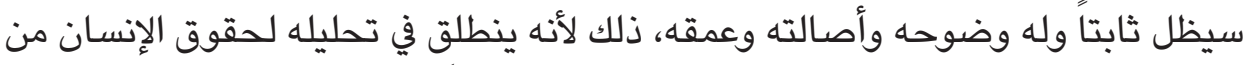

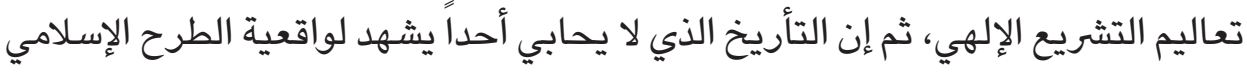
ومصداقية تجرده في مناداته بحقوق الإنسان.

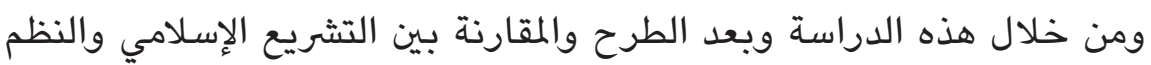

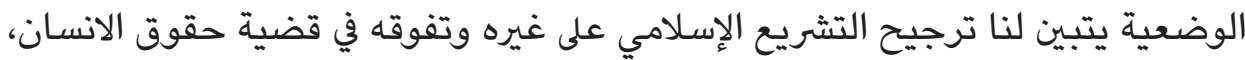

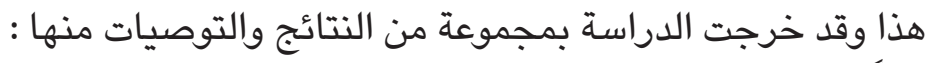

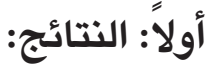

إن التشريع الإسلامي إلاهي المصدر ويمتاز بالثبات وقوة النظريات وأصالة المبادئ

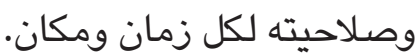


وأما النظم الوضعية فهي تفتقد الثبات وعاجزة عن معالجة قضايا الإنسان وتلبية حاجاته، ذلك لأنها من وضع الإنسان الذي يعتريه العجز والتقصير وتقلب المزاج من وقت وقات

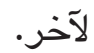

قواعد التشريع الإسلامي تنظم عمل الإنسان وتوجهه إلى الإيمان بالله وفعل الطاعات

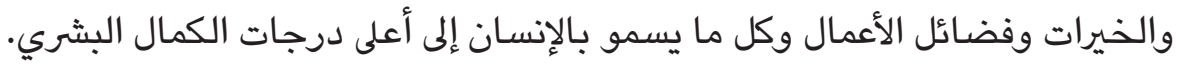

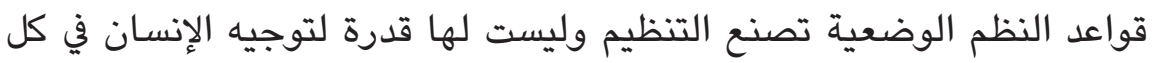
مصالحه ورعاية شئونه. إن التشريع الإسلامي ذو قوة وصلاحية لتنظيم شؤون الأمة أفراداً وجماعات مهما

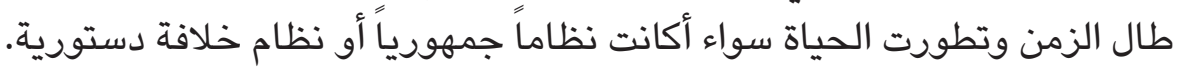
النظم الوضعية نصوصها جامدة وتفتقر المرونة وصلاحية التطبيق والاستمرارية،

$$
\text { ثانياً: التوصيات حول قضية الساعة. }
$$

على المسلمين التمسك بتعاليم دينهم الحنيف والعمل بمقتضاه.

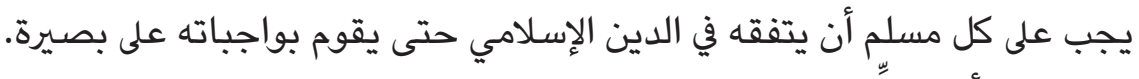

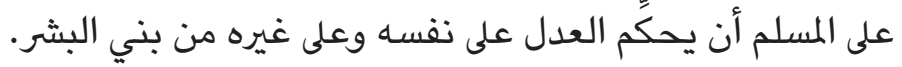
القيام بنشر دعوة الإسلام وإبلاغ تعاليمه إلى الناس.

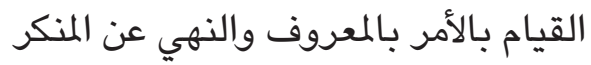

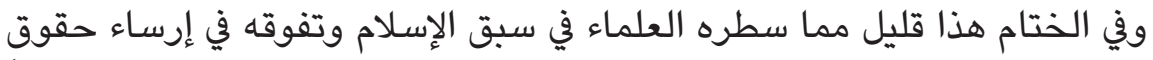
الإنسان ومنع استعباده، عسى أن يكون فيها أبلغ الرد على شبهات أعداء أعداء الإسلام وتثبيتاً

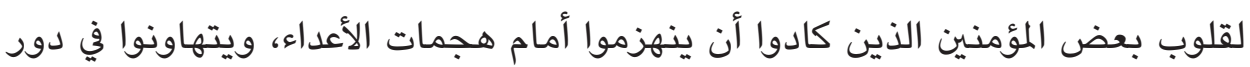

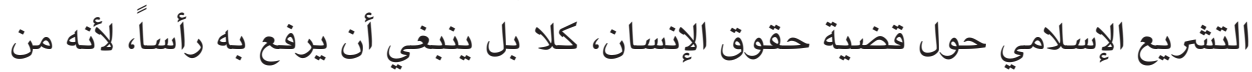

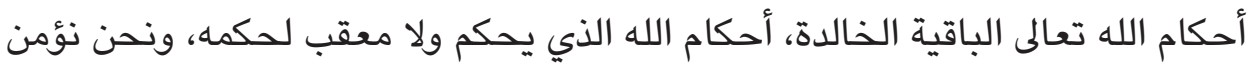

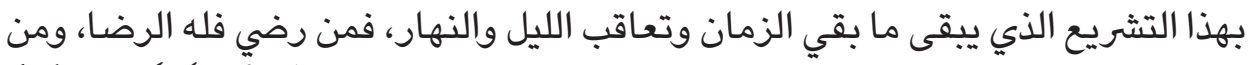

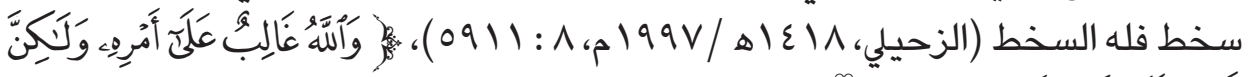

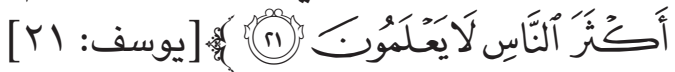

المراجع: أبو داود، سليمان بن الأشعث السِّجنْتاني. تحقيق: صدقي محمد جميل. د.ت. السنن.

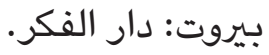


أحمد بن حنبل. بـ 99 ام. المسند. الطبعة الأولى. بيروت: دار الكتب العلمية.

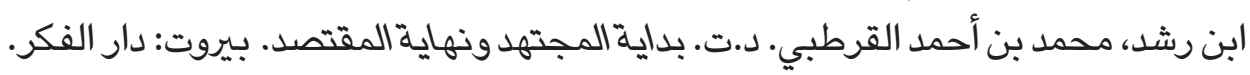

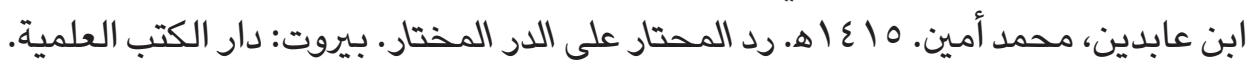

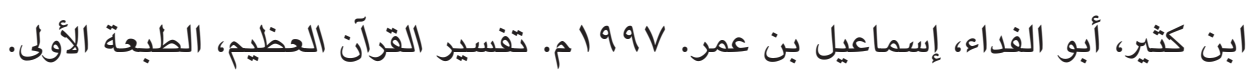

$$
\text { بيروت: دار الفكر. }
$$

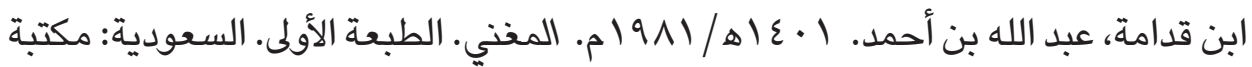

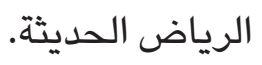

الأشقر، سليمان بن عبد الله. د.ت. زبدة التفسير من فتح القدير. الطبعة الأولى. الكويت:

$$
\text { وزارة الأوقاف. }
$$

البخاري، محمد بن إسماعيل. تحقيق: نور الدين محمد بن عبد الهادي السندي. د. ت.

الجامع المسند الصحيح = صحيح البخاري. مصر: المكتبة التوفيقية.

البوطي، محمد سعيد رمضان. 9 V9 م. فقه السيرة. الطبعة الأولى. بيروت: دار الفكر.

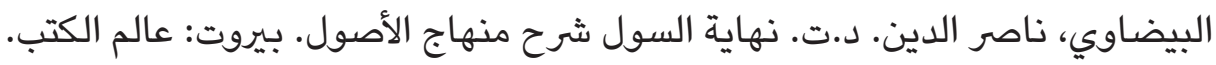

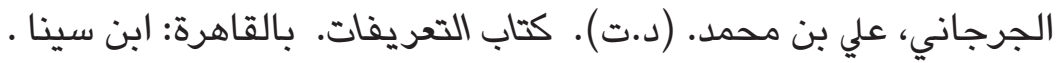

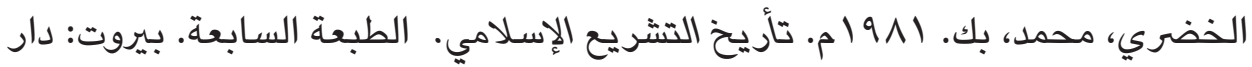

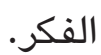

الدسوقي، ابن عرفة، محمد بن أحمد. 1997 م. حاشية الدسوقي على الشرح الكبير.

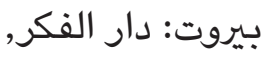

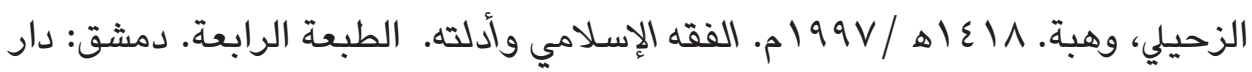

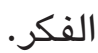

سيد قطب، إبراهيم حسين. راع I أهـ في ظلال القرآن. الطبعة السابعة عشر. بيروت

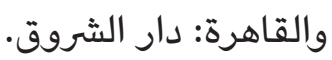

الشافعي، محمد بن إدريس. إثراف محمد النجار، من علماء الأزهر. د. ت. الأم. بيروت:

$$
\text { دارالمعرفة. }
$$

الشربيني، محمد الخطيب. د.ت. مغني المحتاج. بيروت: دار إحياء التراث العربي.

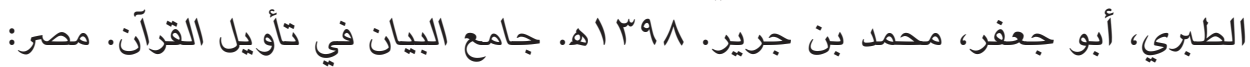

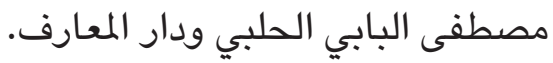
عودة، عبد القادر. د.ت. التشريح الجنائي الإسلامي. بيروت: دار المعار الكتب. 


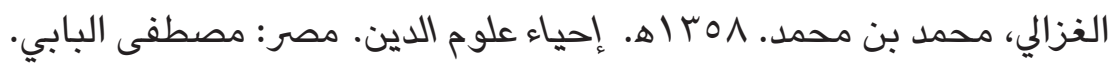

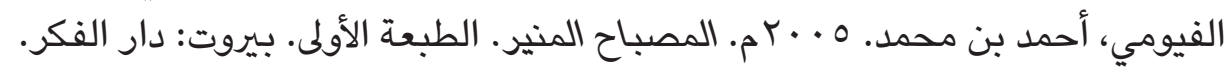
القرضاوي، يوسف. الثانية. بيروت: المكتب الإسلامي. القرطبي، أبو عبد الله، محمد بن أحمد بن أبي بكر. تحقيق: أحمد البردئ البردني وإبراهيم

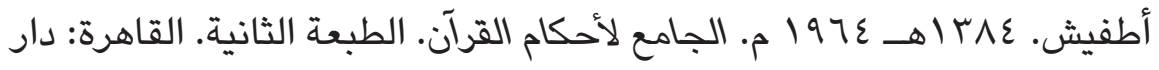

$$
\text { الكتب المصرية. }
$$

مالك بن أنس. تحقيق: محمد فؤاد عبد الباقي. 1 · ·. م. الموطأ. الطبعة الأولى. الخرطوم - السودان: الدار السودانية للكتب.

مسلم، ابن الحجاج النيسابوري. . ㄷم. المسند الصحيح المختصر. الطبعة الثانية.

$$
\text { الأمم المتحدة. الإعلان العالمي لـعودية: دار السلام للنشر. لحقوق الإنسان. }
$$

http://www.un.org/ar/universal-declaration-human-rights/

$$
\text { فهرس حقوق الإنسان في الدول العربية }
$$


